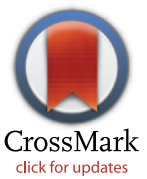

click for updates
RESEARCH ARTICLE

\section{Dengue in the Middle East and North Africa: A Systematic Review}

\author{
John M. Humphrey ${ }^{1}$, Natalie B. Cleton ${ }^{2,3}$, Chantal B. E. M. Reusken ${ }^{2}$, Marshall \\ J. Glesby ${ }^{1,4}$, Marion P. G. Koopmans ${ }^{2,3}$, Laith J. Abu-Raddad ${ }^{4,5,6}$ \\ 1 Division of Infectious Diseases, Department of Medicine, Weill Cornell Medical College, New York, New \\ York, United States of America, 2 Erasmus Medical Centre, Rotterdam, The Netherlands, 3 National Institute \\ for Public Health and Environment (RIVM), Bilthoven, The Netherlands, 4 Department of Healthcare Policy \\ and Research, Weill Cornell Medical College, Cornell University, New York, New York, United States of \\ America, 5 Infectious Disease Epidemiology Group, Weill Cornell Medical College in Qatar, Cornell \\ University, Qatar Foundation, Education City, Doha, Qatar, 6 College of Public Health, Hamad bin Khalifa \\ University, Qatar Foundation, Education City, Doha, Qatar \\ * john.m.humphrey@gmail.com
}

\section{Abstract}

\section{Gopenaccess}

Citation: Humphrey JM, Cleton NB, Reusken CBEM, Glesby MJ, Koopmans MPG, Abu-Raddad LJ (2016) Dengue in the Middle East and North Africa: A Systematic Review. PLoS Negl Trop Dis 10(12): e0005194. doi:10.1371/journal. pntd.0005194

Editor: Olaf Horstick, University of Heidelberg, GERMANY

Received: March 25, 2016

Accepted: November 17, 2016

Published: December 7, 2016

Copyright: ๑ 2016 Humphrey et al. This is an open access article distributed under the terms of the Creative Commons Attribution License, which permits unrestricted use, distribution, and reproduction in any medium, provided the original author and source are credited.

Data Availability Statement: All relevant data are within the paper and its Supporting Information files.

Funding: This publication was made possible by support provided by the Biomedical Research Program and the Biostatistics, Epidemiology, and Biomathematics Research Core at the Weill Cornell Medical College in Qatar. JMH received support from NIH Research Training Grant T32 Al007613. The statements made herein are solely the responsibility of the authors. The funders had no role in study design, data collection and analysis,

\section{Background}

Dengue virus (DENV) infection is widespread and its disease burden has increased in past decades. However, little is known about the epidemiology of dengue in the Middle East and North Africa (MENA).

\section{Methodology / Principal Findings}

Following Cochrane Collaboration guidelines and reporting our findings following PRISMA guidelines, we systematically reviewed available records across MENA describing dengue occurrence in humans (prevalence studies, incidence studies, and outbreak reports), occurrence of suitable vectors (Aedes aegypti and Aedes albopictus), and DENV vector infection rates. We identified 105 human prevalence measures in 13 of 24 MENA countries; 81 outbreaks reported from 9 countries from 1941-2015; and reports of Ae. aegypti and/or Ae. albopictus occurrence in 15 countries. The majority of seroprevalence studies were reported from the Red Sea region and Pakistan, with multiple studies indicating $>20 \%$ DENV seroprevalence in general populations (median 25\%, range 0-62\%) in these subregions. Fifty percent of these studies were conducted prior to 1990. Multiple studies utilized assays susceptible to serologic cross-reactions and $5 \%$ of seroprevalence studies utilized viral neutralization testing. There was considerable heterogeneity in study design and outbreak reporting, as well as variability in subregional study coverage, study populations, and laboratory methods used for diagnosis.

\section{Conclusions / Significance}

DENV seroprevalence in the MENA is high among some populations in the Red Sea region and Pakistan, while recent outbreaks in these subregions suggest increasing incidence of DENV which may be driven by a variety of ecologic and social factors. However, there is 
decision to publish, or preparation of the manuscript.

Competing Interests: The authors have declared that no competing interests exist. insufficient study coverage to draw conclusions about Aedes or DENV presence in multiple MENA countries. These findings illustrate the epidemiology of DENV in the MENA while revealing priorities for DENV surveillance and Aedes control.

\section{Author Summary}

Dengue is a mosquito-transmitted flavivirus whose global distribution and disease incidence has increased in recent decades. In the Middle East and North Africa, the epidemiology of dengue remains poorly characterized despite increasing reports of outbreaks and transmission in new areas. In order to understand the evidence supporting the epidemiology of this virus in the region and the areas in need of further research, we conducted a systematic review of studies reporting human prevalence, incidence, and infection rates in the virus' main mosquito vectors, Aedes aegypti and Aedes albopictus. Among the studies identified, the Red Sea subregion and Pakistan reported the highest seroprevalence estimates for dengue. However, we encountered substantial heterogeneity in the distribution, quality, and quantity of published studies. These findings inform future research and surveillance priorities for DENV in the MENA region.

\section{Introduction}

Dengue virus (DENV) is a globally distributed flavivirus with nearly 400 million estimated annual infections and a growing geographic distribution and disease burden [1-3]. DENV has a historic presence in the Middle East and North Africa (MENA), with outbreaks of dengue and dengue-like disease reported across much of the Eastern Mediterranean region in the $19^{\text {th }}$ and early $20^{\text {th }}$ centuries $[4,5]$. Today, DENV may be resurging in the MENA $[6,7]$, with recent outbreaks of unprecedented or previously unrecognized magnitude occurring in the Arabian Peninsula and Pakistan [8, 9], and a 2015 outbreak in Egypt that occurred following a decadeslong absence of reported cases from that country [10]. Still, despite increasing global concern about the threat of Aedes-transmitted arboviruses, the epidemiology of DENV in the MENA region remains largely uncharacterized.

Understanding the epidemiology of DENV in the MENA represents an ongoing challenge for multiple reasons [11]. Inadequate human and vector surveillance, non-reporting of illness syndromes, and poor diagnostic capacity limit DENV detection in many countries, resulting in delays in outbreak recognition and sparse data with which to estimate disease burden and infection rates [12-14]. Case series, outbreak reports, and national notification reports, which contribute much to the epidemiologic knowledge of DENV, may also contain bias in reflecting only those areas with sufficient capacity to detect and report DENV when it occurs [1]. Moreover, clinical diagnosis of DENV infection in the absence of laboratory confirmation is often unreliable [12, 15-18]. Cross-sectional serologic surveys for DENV exposure have the potential to shed light on the broader population burden of DENV without these biases. However, serologic cross-reactions among antibody-based assays for flaviviruses can limit the reliability of such studies in the absence of confirmatory testing, though the latter is difficult to perform and often unavailable $[19,20]$.

To further the knowledge of the epidemiology of DENV in the MENA, we undertook a comprehensive summary and appraisal of published DENV prevalence, incidence, vector infection rates, reported outbreaks, and Aedes occurrence reports in the MENA region. This 
report aims to enhance the understanding of the epidemiology of DENV in the MENA while informing priorities for future research.

\section{Materials and Methods Objectives}

The objective of this study was to characterize the epidemiology of DENV in the MENA region through a systematic review of human prevalence and incidence studies and infection rates in Aedes mosquitoes. We also aimed to summarize reported human outbreaks and Ae. aegypti and Ae. albopictus occurrence in the region. The original search was last updated on December 9, 2015.

\section{Eligibility criteria}

Table 1 displays the eligibility criteria. In brief, studies containing primary prevalence, incidence, and vector infection rates for DENV in the MENA region were considered eligible for the systematic review. Publication year was not considered an inclusion criterion, as we reasoned that the historic distribution of DENV could be useful in understanding its current epidemiology by depicting ecologically viable regions in which DENV transmission continues to occur or could re-emerge. For incidence studies, those that reported the number of acute infections or seroconversions over any time interval were eligible. Vector infection rate studies were included if they contained a measure of the estimated proportion of infected Ae. aegypti or Ae. albopictus at a given time and setting in the MENA region.

\section{Outcomes}

For the systematic review, the primary outcomes were DENV human prevalence, incidence, and vector infection rates in the MENA region. Secondary outcomes were reports of dengue outbreaks and vector occurrence.

\section{Data sources and search strategy}

We conducted a systematic search for DENV in the MENA following Cochrane Collaboration guidelines [21] and reported our findings using the Preferred Reporting Items for Systematic reviews and Meta-analyses (PRISMA) guidelines [22]. The PRISMA checklist is found in S1 Fig and our search criteria in S2 Fig. Briefly, we searched PubMed, Embase, the World Health Organization (WHO) Index Medicus for the Eastern Mediterranean Region and WHO African Index Medicus without publication date or language restrictions, using text and $\mathrm{MeSH} /$

Table 1. Criteria for study inclusion or exclusion.

\begin{tabular}{|c|c|c|}
\hline Study type & Inclusion Criteria & Exclusion Criteria \\
\hline \multicolumn{3}{|c|}{$\begin{array}{l}\text { Human prevalence/ } \\
\text { incidence }\end{array}$} \\
\hline $\begin{array}{l}\text { publication } \\
\text { characteristics }\end{array}$ & $\begin{array}{l}\text { Full article or abstract published in any year, language, setting, } \\
\text { or population in the MENA region; any seroconversion interval } \\
\text { for incidence studies }\end{array}$ & $\begin{array}{l}\text { Case reports, case series, editorials, letters to editors, reviews, } \\
\text { commentaries, qualitative studies, basic science research studies, } \\
\text { studies from countries outside the MENA region }\end{array}$ \\
\hline study design & Any randomized or non-randomized design & Non-empirical research/modelled data \\
\hline outcomes & $\begin{array}{l}\text { DENV seroprevalence or prevalence of laboratory-confirmed } \\
\text { infection; DENV incidence (by any laboratory method) }\end{array}$ & No human prevalence or incidence measure reported \\
\hline $\begin{array}{l}\text { Vector infection } \\
\text { rate }\end{array}$ & $\begin{array}{l}\text { Reported Ae. aegyptior Ae. albopictus infection rates by any } \\
\text { laboratory method }\end{array}$ & $\begin{array}{l}\text { Basic science research studies, infection rates in other mosquito } \\
\text { species or non-MENA country }\end{array}$ \\
\hline
\end{tabular}

doi:10.1371/journal.pntd.0005194.t001 
Emtree terms exploded to include all subheadings. Our review covered the 23 countries included in the MENA definitions of the WHO/EMRO, World Bank, and the Joint United Nations Programme on HIV/AIDS (UNAIDS) for consistency with earlier regional analyses of various infectious diseases including HIV [23].

\section{Study selection}

For each search, titles and abstracts were imported into Endnote (Thompson Reuters, Philadelphia, PA, USA), duplicates were removed, and were screened by one author (JH) with potential eligibility determined by consensus with a second author (NC) when eligibility was unclear. Full texts of potentially relevant records were retrieved and assessed for eligibility, contacting the author of the report as necessary. Reference lists of all potentially eligible articles and reviews were also searched. In this study, 'report' refers to the document (paper, abstract, or public health record) containing an outcome measure of interest, while 'study' refers to the outcome measure(s) within that report. Hence, reports could contribute more than one study, though multiple reports of the same study were counted only once.

\section{Data Extraction and Synthesis}

Data were extracted by one of the authors $(\mathrm{JH})$ using a pre-piloted data extraction form and entered into a database created in Microsoft Access. Data from reports in English were extracted from the full texts, while reports in French $(n=6)$, Turkish $(n=3)$, Dutch $(n=1)$, and German $(n=1)$ were extracted from the abstracts and full texts with the help of online language software and French, Turkish, and German language speakers [24]. There were no records in other languages. Studies were compiled by country and organized by year, using separate tables for human prevalence, incidence, and vector infection rates. Prevalence studies were further stratified as follows: 1) general prevalence studies measuring the prevalence of anti-DENV antibodies among populations without acute infection (e.g. DENV exposure); and 2) acute DENV infection studies assessing the prevalence of laboratory-confirmed DENV infection in those with a) undifferentiated acute febrile illness (AFI) and b) suspected DENV infection (Table 2). These stratifications were made because of the different study aims and probabilities of having laboratory evidence of DENV infection in each of these populations. Finally, the geographic distribution of all included prevalence studies were mapped according to the first-level administrative division (e.g. state, province) in which each study was conducted (Tableau Software, Seattle, WA, USA).

\section{Risk of bias assessment}

In order to gain a better understanding of the quality of prevalence studies identified through the systematic review, the risk of bias (ROB) was assessed for each study based on the

Table 2. Definitions of human prevalence study populations identified through the systematic review.

\begin{tabular}{l|l}
\hline Study Population & Definition \\
\hline $\begin{array}{l}\text { General } \\
\text { prevalence }\end{array}$ & $\begin{array}{l}\text { Seroprevalence studies reporting anti-DENV IgG prevalence measures among } \\
\text { individuals not suspected to have acute dengue infection, including community } \\
\text { members, blood donors, military, students, and hospitalized patients and outpatients } \\
\text { receiving care for non-febrile illnesses. }\end{array}$ \\
\hline $\begin{array}{l}\text { Acute DENV } \\
\text { infection }\end{array}$ & $\begin{array}{l}\text { Undifferentiated acute febrile illness (AFI): studies for which acute dengue } \\
\text { infection is not differentiated by clinical grounds alone; IgG prevalence measures } \\
\text { obtained during the acute phase of illness is these studies are presumed to reflect } \\
\text { secondary infection. }\end{array}$ \\
\hline & $\begin{array}{l}\text { Suspected dengue infection: studies in which defined or undefined clinical criteria } \\
\text { for probable dengue infection is stated as an inclusion criterion in the study. }\end{array}$ \\
\hline
\end{tabular}

doi:10.1371/journal.pntd.0005194.t002 
Cochrane approach [25] and by evaluating the precision of the reported measures. The methodology for this assessment is similar to that which we have previously developed for reviews of HIV and hepatitis C prevalence in the MENA region [26-28]. Each DENV prevalence measure was considered to have a low, high, or unclear ROB in three domains: sampling methodology, DENV infection ascertainment, and response rate. The latter was defined as the number of tested individuals divided by the number of persons invited to participate in the study [29]. ROB was considered low if (1) sampling was probability-based (i.e. using some form of random selection), (2) DENV prevalence measures included viral neutralization testing (VNT) for general prevalence studies or biological assays (i.e. cell culture, PCR, and NS1 ELISA) for acute infection studies, and (3) response rate was $\geq 80 \%$. Studies with missing information for any of the domains were classified as having unclear ROB for that specific domain. Sampling strategy was not evaluated for acute infection studies because these studies enrolled individuals presenting to a health facility with acute infection, hence, no population-based sampling is needed to capture this population. Studies were considered to have high precision if the number of individuals tested was $\geq 100$. We considered this to be a reasonably sensitive cutoff for precision given the heterogeneous epidemiology of DENV across the region (e.g. a prevalence of $1 \%$ entails a $95 \%$ CI of $0-3 \%$ ).

\section{DENV outbreaks and Aedes distribution}

To supplement the epidemiologic data gathered through the systematic search, reported outbreaks and Ae. aegypti or Ae. albopictus occurrence in the MENA were also sought from the articles retrieved through the search databases as well as through ProMED-MENA and Google Scholar. Given that the characteristics and definitions of dengue outbreaks in the literature are implicitly variable and that there is currently no consensus on how to define such events [30], we broadly included any outbreak report if the author of the report defined the event as an outbreak. Multiple reports of the same outbreak were recorded only once. We manually marked the location of reported outbreaks on the map as well, designating one mark per each firstlevel administrative division in which one or more outbreaks were identified. In a separate map, we mapped the country-level occurrence of Ae. aegypti and Ae. albopictus in order to further inform the existing or potential epidemiology of DENV in the MENA.

\section{Results}

\section{Search results}

The selection process based on PRISMA guidelines is illustrated in Fig 1 [22]. Briefly, the DENV search yielded 1,258 citations, 91 of which were ultimately eligible for inclusion in the study following the addition of 4 reports identified from the bibliographies of relevant reports and reviews. Four studies from the 1970-80s were excluded that contained DENV seroprevalence of $0-11 \%$ in wild and domestic animals in Pakistan, Tunisia, and Turkey, though these may have represented cross-reactions with other flaviviruses [31-34].

\section{Characteristics of included studies}

A total of 105 human prevalence studies for DENV were identified from eligible reports (Table 3). These studies covered 13 of 24 MENA countries and were conducted from 19622015. The geographic distribution of these studies is illustrated in Fig 2, and Table 4 contains a frequency summary of these studies. Anti-DENV antibodies were detected in 12 of 13 countries in which studies were reported with a single 1973 study from Libya reporting $0 \%$ seroprevalence [35]. The highest number of studies were reported from Pakistan $(n=32)$ and 


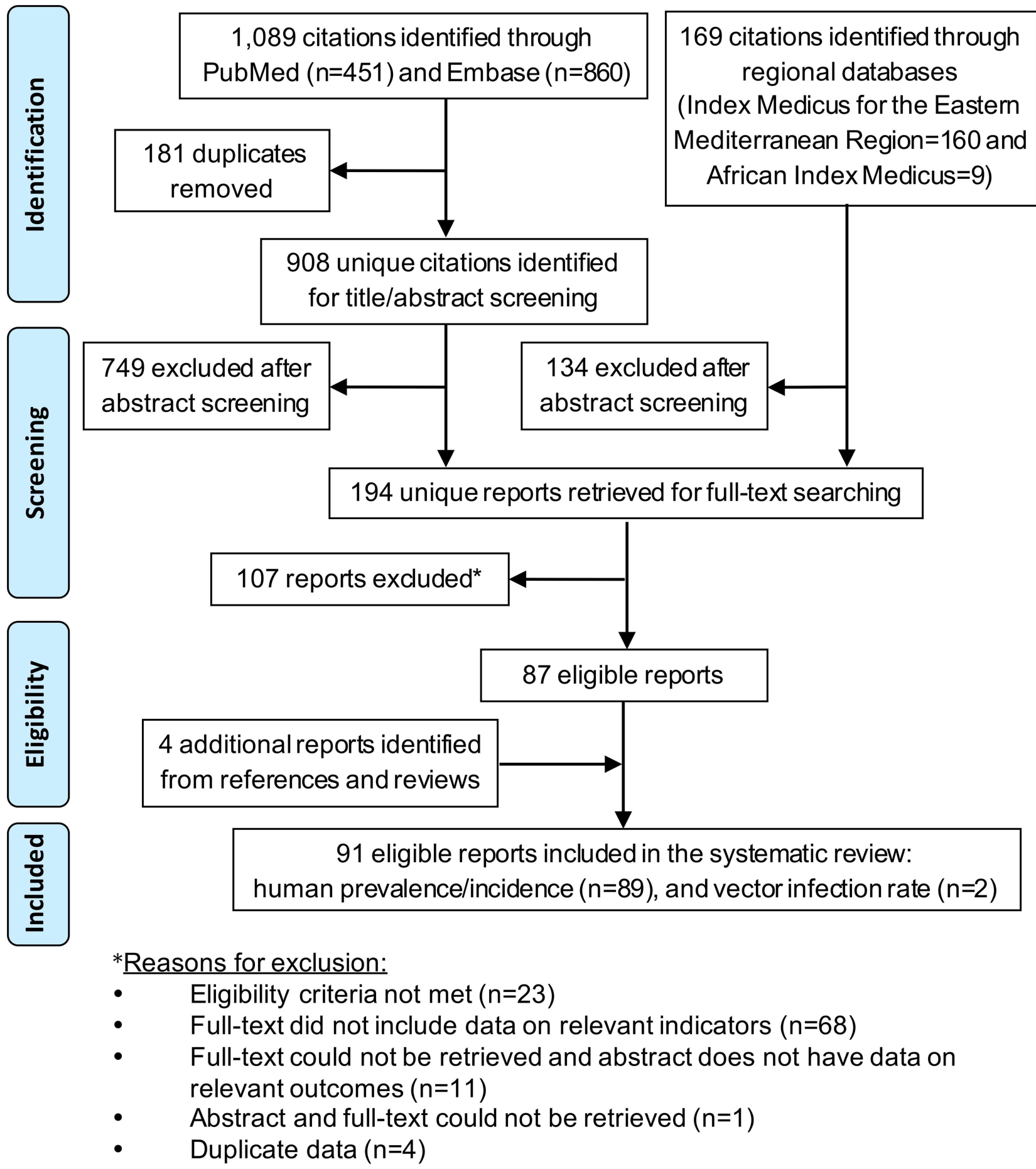

Fig 1. PRISMA flow diagram of article selection. Flow diagram for dengue prevalence, incidence, and vector infection rates in the Middle East and North Africa.

doi:10.1371/journal.pntd.0005194.g001

Sudan $(\mathrm{n}=16)$, most of which targeted populations with acute DENV infection (undifferentiated AFI or suspected dengue infection). Among general population studies, IgG prevalence measures ranged from $0 \%$ to $61 \%$ and were reported from Djibouti ( $n=4,0-21 \%)$, Egypt $(\mathrm{n}=4,0-7 \%)$, Iran $(\mathrm{n}=3,0-7 \%)$, Kuwait $(\mathrm{n}=3,0-56 \%)$, Lebanon $(\mathrm{n}=3,0-61 \%)$, Pakistan 
Table 3. Human prevalence studies for dengue virus in the Middle East and North Africa $(n=105)$.

\begin{tabular}{|c|c|c|c|c|c|c|c|c|c|c|c|}
\hline $\begin{array}{l}\text { Country, } \\
\text { Ref. }\end{array}$ & $\begin{array}{l}\text { Year(s) } \\
\text { of } \\
\text { study* }\end{array}$ & $\begin{array}{c}\text { City or } \\
\text { governorate }\end{array}$ & $\begin{array}{c}\text { Setting; } \\
\text { population } \\
\text { (age range, } \\
\text { years) }\end{array}$ & Sampling & $\begin{array}{l}\text { Assay } \\
\text { type }\end{array}$ & $\begin{array}{l}\text { Assay } \\
\text { make }^{\dagger}\end{array}$ & \begin{tabular}{|c|} 
Target \\
Protein
\end{tabular} & \begin{tabular}{|c|} 
Assay \\
serotype
\end{tabular} & $\begin{array}{c}\text { Sample } \\
\text { size }\end{array}$ & Prevalence & $\begin{array}{l}\text { Additional } \\
\text { testing \& } \\
\text { Comments }\end{array}$ \\
\hline \multicolumn{12}{|c|}{ Afghanistan $(n=1)$} \\
\hline Elyan [44] & $\begin{array}{c}2008- \\
10\end{array}$ & $\begin{array}{l}\text { Uruzgon, } \\
\text { Helmand, } \\
\text { Kandahar }\end{array}$ & $\begin{array}{l}\text { Hospital; AFI } \\
\text { patients (20- } \\
59)\end{array}$ & Conv. & ELISA & PanBio & Env & $1-4$ & 913 & $19.2 \% * *$ & $\begin{array}{c}2.6 \%(8 / 312) \\
\text { were IgM+; } \\
\text { observed } \\
\text { cross-reaction } \\
\text { to WNV, TBEV }\end{array}$ \\
\hline \multicolumn{12}{|c|}{ Djibouti $(n=6)$} \\
\hline \multirow[t]{3}{*}{ Salah [45] } & 1987 & Djibouti City & $\begin{array}{l}\text { Military; } \\
\text { healthy } \\
\text { soldiers }\end{array}$ & Conv. & IIFA & In-house & wv & 2 & 50 & $0 \%$ & \\
\hline & & Randa & $\begin{array}{c}\text { Rural } \\
\text { community; } \\
\text { general pop. }\end{array}$ & Conv. & IIFA & In-house & wv & 2 & 69 & $0 \%$ & \\
\hline & & Djibouti City & $\begin{array}{l}\text { Hospital; AFI } \\
\text { patients }\end{array}$ & Conv. & IIFA & In-house & wv & 2 & 41 & $0 \%$ & \\
\hline \multirow[t]{4}{*}{ Rodier [37] } & 1991 & Djibouti City & $\begin{array}{c}\text { Clinical } \\
\text { setting; AFI } \\
\text { patients }(1-55)\end{array}$ & Conv. & $\begin{array}{c}\text { ELISA } \\
\operatorname{IgM}\end{array}$ & In-house & wv & 1 & 91 & $7.7 \% * *$ & $\begin{array}{c}3.7 \%(1 / 27) \\
\text { were VNT+; } \\
\text { multiple } \\
\text { observed } \\
\text { cross- } \\
\text { reactions }\end{array}$ \\
\hline & & & & Conv. & $\begin{array}{c}\text { ELISA } \\
\text { IgM }\end{array}$ & In-house & wv & 2 & same & $25.2 \% * *$ & $\begin{array}{c}11.1 \%(3 / 27) \\
\text { were VNT+; } \\
\text { multiple } \\
\text { observed } \\
\text { cross- } \\
\text { reactions }\end{array}$ \\
\hline & & & & Conv. & $\begin{array}{l}\text { ELISA } \\
\text { IgM }\end{array}$ & In-house & wv & 3 & same & $16.4 \% * *$ & $\begin{array}{l}\text { multiple } \\
\text { observed } \\
\text { cross- } \\
\text { reactions }\end{array}$ \\
\hline & & & & Conv. & $\begin{array}{l}\text { ELISA } \\
\text { IgM }\end{array}$ & In-house & wv & 4 & same & $18.7 \% * *$ & $\begin{array}{l}\text { multiple } \\
\text { observed } \\
\text { cross- } \\
\text { reactions }\end{array}$ \\
\hline Fauld [46] & 2011 & Djibouti City & $\begin{array}{l}\text { Animal } \\
\text { quarantine } \\
\text { station; } \\
\text { workers }\end{array}$ & Conv. & IIFA & Eurolmmun & wv & $1-4$ & 10 & $10.0 \% * *$ & $\begin{array}{l}\text { not cross- } \\
\text { reactive to } \\
\text { WNV }\end{array}$ \\
\hline Andayi [47] & $\begin{array}{c}2010- \\
11\end{array}$ & Djibouti City & $\begin{array}{l}\text { Community; } \\
\text { general pop. } \\
(<1-100)\end{array}$ & SRS & ELISA & PanBio & Env & $1-4$ & 911 & $21.8 \%$ & \\
\hline \multicolumn{12}{|l|}{ Egypt $(n=5)$} \\
\hline \multirow[t]{3}{*}{$\begin{array}{l}\text { Mohammed } \\
\text { [48] }\end{array}$} & 1966 & Abyss & $\begin{array}{c}\text { rural } \\
\text { community; } \\
\text { general pop. }\end{array}$ & Conv. & $\mathrm{HI}$ & In-house & wv & 1 & 29 & $7.0 \% * *$ & $\begin{array}{l}\text { possible cross- } \\
\text { reaction to } \\
\text { WNV }\end{array}$ \\
\hline & & & & & $\mathrm{HI}$ & In-house & wv & 4 & same & $3.0 \% * *$ & $\begin{array}{c}\text { possible cross- } \\
\text { reaction to } \\
\text { WNV }\end{array}$ \\
\hline & & Alexandria & $\begin{array}{c}\text { urban } \\
\text { community; } \\
\text { general pop. }\end{array}$ & Conv. & $\mathrm{HI}$ & In-house & wv & 1 & 55 & $4.0 \% * *$ & $\begin{array}{c}\text { possible cross- } \\
\text { reaction to } \\
\text { WNV }\end{array}$ \\
\hline
\end{tabular}

(Continued) 
Table 3. (Continued)

\begin{tabular}{|c|c|c|c|c|c|c|c|c|c|c|c|}
\hline $\begin{array}{l}\text { Country, } \\
\text { Ref. }\end{array}$ & $\begin{array}{l}\text { Year(s) } \\
\text { of } \\
\text { study* }\end{array}$ & $\begin{array}{c}\text { City or } \\
\text { governorate }\end{array}$ & $\begin{array}{c}\text { Setting; } \\
\text { population } \\
\text { (age range, } \\
\text { years) }\end{array}$ & Sampling & $\begin{array}{l}\text { Assay } \\
\text { type }\end{array}$ & $\begin{array}{l}\text { Assay } \\
\text { make }^{\dagger}\end{array}$ & \begin{tabular}{|c|} 
Target \\
Protein
\end{tabular} & $\begin{array}{c}\text { Assay } \\
\text { serotype }\end{array}$ & $\begin{array}{c}\text { Sample } \\
\text { size }\end{array}$ & Prevalence & $\begin{array}{l}\text { Additional } \\
\text { testing \& } \\
\text { Comments }\end{array}$ \\
\hline & & & & & $\mathrm{HI}$ & In-house & wv & 4 & same & $5.0 \% * *$ & $\begin{array}{c}\text { possible cross- } \\
\text { reaction to } \\
\text { WNV }\end{array}$ \\
\hline \multirow[t]{2}{*}{$\begin{array}{l}\text { Mohammed } \\
{[49]}\end{array}$} & 1968 & Alexandria & $\begin{array}{c}\text { Hospital; AFI } \\
\text { patients (3-13) }\end{array}$ & Conv. & $\mathrm{HI}, \mathrm{CF}$ & In-house & wv & 1 & 120 & $0 \% * *$ & $\begin{array}{c}0 \%(0 / 48) \\
\text { were } \\
\text { convalescent + }\end{array}$ \\
\hline & & Alexandria & $\begin{array}{c}\text { Clinical } \\
\text { setting; adults }\end{array}$ & Conv. & $\mathrm{HI}$ & In-house & wv & 1 & 78 & $0 \%$ & \\
\hline Darwish [50] & 1969 & Multiple & $\begin{array}{l}\text { University; } \\
\text { students }\end{array}$ & Conv. & $\mathrm{HI}$ & In-house & wv & 1 & 1133 & $0.3 \%$ & \\
\hline \multicolumn{12}{|l|}{$\operatorname{Iran}(n=4)$} \\
\hline Saidi [51] & 1970 & Multiple & $n / s$ & $\mathrm{n} / \mathrm{s}$ & $\mathrm{HI}$ & In-house & wv & $1,2,3$ & 394 & $6.0 \% * *$ & $\begin{array}{c}\text { possible cross- } \\
\text { reaction to } \\
\text { WNV }\end{array}$ \\
\hline Saidi [52] & $\begin{array}{c}1970- \\
71\end{array}$ & $\begin{array}{l}\text { Caspian } \\
\text { region }\end{array}$ & $\begin{array}{l}\text { Community; } \\
\text { children (1-6) }\end{array}$ & Conv. & $\mathrm{HI}$ & In-house & wv & 2 & 100 & $0 \%$ & \\
\hline $\begin{array}{l}\text { Chinikar } \\
\text { [53] }\end{array}$ & $\begin{array}{c}2000- \\
12\end{array}$ & Countrywide & $\begin{array}{l}\text { Clinical } \\
\text { setting; AFI } \\
\text { patients }\end{array}$ & Conv. & ELISA & Vircell & wv & 1,2 & 300 & $3.3 \%$ & $\begin{array}{c}\text { 3.3\% }(10 / 300) \\
\text { were IgM+; } \\
\text { DEN-1,2 were } \\
\text { positive by } \\
\text { PCR }\end{array}$ \\
\hline Aghaie [14] & 2014 & $\begin{array}{l}\text { Sistan- } \\
\text { Baluchestan }\end{array}$ & $\begin{array}{l}\text { blood donor } \\
\text { center; general } \\
\text { pop. }\end{array}$ & Conv. & ELISA & PanBio & Env & $1-4$ & 540 & $7.6 \%$ & $\begin{array}{c}78 \%(32 / 41) \\
\text { ELISA+ were } \\
\text { IFA+ }\end{array}$ \\
\hline \multicolumn{12}{|l|}{ Kuwait $(n=8)$} \\
\hline \multirow[t]{2}{*}{ Ibrahim [54] } & $\begin{array}{c}1966- \\
68\end{array}$ & Multiple & $\begin{array}{c}\text { Multiple } \\
\text { settings; blood } \\
\text { donors, non- } \\
\text { AFI patients, } \\
\text { children (1-60) }\end{array}$ & Conv. & $\mathrm{HI}$ & In-house & wv & 1 & 627 & $6.5 \% * *$ & $\begin{array}{l}\text { not cross- } \\
\text { reactive to } \\
\text { DEN-2 or } \\
\text { WNV }\end{array}$ \\
\hline & & & & & $\mathrm{HI}$ & In-house & wv & 2 & same & $8.1 \% * *$ & $\begin{array}{l}\text { not cross- } \\
\text { reactive to } \\
\text { DEN-1 or } \\
\text { WNV }\end{array}$ \\
\hline \multirow[t]{2}{*}{$\begin{array}{l}\text { Al-Nakib } \\
{[55]}\end{array}$} & $\begin{array}{c}1979- \\
82\end{array}$ & Jabriya & $\begin{array}{l}\text { Hospital; non- } \\
\text { AFI patients } \\
(0-60+)\end{array}$ & SRS & $\mathrm{HI}$ & In-house & wv & 1 & 502 & $3.2 \% * *$ & $\begin{array}{l}\text { not cross- } \\
\text { reactive to } \\
\text { DEN-2 or } \\
\text { WNV }\end{array}$ \\
\hline & & & & & $\mathrm{HI}$ & In-house & wv & 2 & same & $8.4 \% * *$ & $\begin{array}{l}\text { all were cross- } \\
\text { reactive to } \\
\text { DEN-1, WNV, } \\
\text { or TBEV }\end{array}$ \\
\hline \multirow[t]{3}{*}{ Pacsa [56] } & $2002^{*}$ & Multiple & $\begin{array}{l}\text { n/s; Kuwaiti } \\
\text { nationals }\end{array}$ & $n / s$ & $\begin{array}{l}\text { ELISA } \\
\text { and } \\
\text { IgG } \\
\text { blot }\end{array}$ & $\begin{array}{l}\text { CDC and } \\
\text { Genlab }\end{array}$ & wv & $1-4$ & 425 & $13.9 \%$ & $\begin{array}{l}\text { only DENV } \\
1-3 \text { were } \\
\text { positive }\end{array}$ \\
\hline & & & $\begin{array}{l}\text { n/s; Kuwait } \\
\text { Bedouins }\end{array}$ & $\mathrm{n} / \mathrm{s}$ & $\begin{array}{l}\text { ELISA } \\
\text { and } \\
\text { IgG } \\
\text { blot }\end{array}$ & $\begin{array}{l}\text { CDC and } \\
\text { Genlab }\end{array}$ & wv & $1-4$ & 47 & $0 \%$ & \\
\hline & & & $\begin{array}{c}\mathrm{n} / \mathrm{s} \\
\text { expatriates } \\
\text { from South } \\
\text { Asia }\end{array}$ & $n / s$ & $\begin{array}{l}\text { ELISA } \\
\text { and } \\
\text { IgG } \\
\text { blot }\end{array}$ & $\begin{array}{l}\text { CDC and } \\
\text { Genlab }\end{array}$ & wv & $1-4$ & 266 & $37 \%$ & $\begin{array}{l}\text { only DENV } \\
1-3 \text { were } \\
\text { positive }\end{array}$ \\
\hline
\end{tabular}

(Continued) 
Table 3. (Continued)

\begin{tabular}{|c|c|c|c|c|c|c|c|c|c|c|c|}
\hline \multirow[t]{4}{*}{$\begin{array}{l}\text { Country, } \\
\text { Ref. }\end{array}$} & $\begin{array}{l}\text { Year(s) } \\
\text { of } \\
\text { study* }\end{array}$ & $\begin{array}{c}\text { City or } \\
\text { governorate }\end{array}$ & $\begin{array}{c}\text { Setting; } \\
\text { population } \\
\text { (age range, } \\
\text { years) }\end{array}$ & Sampling & $\begin{array}{l}\text { Assay } \\
\text { type }\end{array}$ & $\begin{array}{l}\text { Assay } \\
\text { make }^{\dagger}\end{array}$ & $\begin{array}{c}\text { Target } \\
\text { Protein }\end{array}$ & $\begin{array}{c}\text { Assay } \\
\text { serotype }\end{array}$ & $\begin{array}{c}\text { Sample } \\
\text { size }\end{array}$ & Prevalence & $\begin{array}{l}\text { Additional } \\
\text { testing\& } \\
\text { Comments }\end{array}$ \\
\hline & & & $\begin{array}{c}\mathrm{n} / \mathrm{s} ; \\
\text { expatriates } \\
\text { from } \\
\text { Southeast } \\
\text { Asia }\end{array}$ & $n / s$ & $\begin{array}{l}\text { ELISA } \\
\text { and } \\
\text { IgG } \\
\text { blot }\end{array}$ & $\begin{array}{l}\text { CDC and } \\
\text { Genlab }\end{array}$ & wv & $1-4$ & 31 & $56.6 \%$ & $\begin{array}{l}\text { only DENV } \\
1-3 \text { were } \\
\text { positive }\end{array}$ \\
\hline & & & $\begin{array}{c}\mathrm{n} / \mathrm{s} \\
\text { expatriates } \\
\text { from Middle } \\
\text { East }\end{array}$ & $n / s$ & $\begin{array}{l}\text { ELISA } \\
\text { and } \\
\text { IgG } \\
\text { blot }\end{array}$ & $\begin{array}{l}\text { CDC and } \\
\text { Genlab }\end{array}$ & wv & $1-4$ & 140 & $25 \%$ & $\begin{array}{l}\text { only DENV } \\
1-3 \text { were } \\
\text { positive }\end{array}$ \\
\hline & & & $\begin{array}{l}\text { Hospital; } \\
\text { returned } \\
\text { travelers with } \\
\text { dengue-like } \\
\text { illness }\end{array}$ & $n / s$ & $\begin{array}{l}\text { ELISA } \\
\text { IgM }\end{array}$ & PanBio & Env & $1-4$ & 210 & $9.0 \%$ & $\begin{array}{c}\text { only DENV } \\
\text { 1-3 were } \\
\text { positive; } 10 \% \\
\text { (2/19) lgM } \\
\text { + were PCR+ }\end{array}$ \\
\hline \multicolumn{12}{|c|}{ Lebanon $(n=3)$} \\
\hline \multirow[t]{2}{*}{$\begin{array}{l}\text { Garabedian } \\
{[5]}\end{array}$} & $\begin{array}{c}1962- \\
65\end{array}$ & Multiple & $\begin{array}{l}\text { Community; } \\
\text { general pop. } \\
(0-41+)\end{array}$ & SRS & $\mathrm{HI}$ & In-house & wv & 2 & 113 & $61.9 \% * *$ & $\begin{array}{c}\text { observed } \\
\text { cross-reaction } \\
\text { with WNV, } \\
\text { YFV }\end{array}$ \\
\hline & & Multiple & $\begin{array}{l}\text { Community; } \\
\text { general pop. } \\
(0-41+)\end{array}$ & SRS & $\mathrm{HI}$ & In-house & wv & 1 & 171 & $49.1 \% * *$ & $\begin{array}{c}\text { observed } \\
\text { cross-reaction } \\
\text { with WNV, } \\
\text { YFV }\end{array}$ \\
\hline \multirow[t]{2}{*}{ Hatem [57] } & 1969 & Beirut & $\mathrm{n} / \mathrm{s}$ & $n / s$ & $\mathrm{HI}$ & In-house & wv & 2 & 126 & $0 \%$ & \\
\hline & & & $\mathrm{n} / \mathrm{s}$ & $n / s$ & $\mathrm{HI}$ & In-house & wv & 1 & same & $4.0 \% * *$ & $\begin{array}{l}\text { observed } \\
\text { cross-reaction } \\
\text { with WNV }\end{array}$ \\
\hline \multicolumn{12}{|l|}{ Libya $(n=1)$} \\
\hline Darwish [35] & 1973 & Sebha & $\begin{array}{l}\text { community } \\
\text { and clinic; } \\
\text { children, non- } \\
\text { AFI patients }\end{array}$ & Conv. & $\mathrm{HI}$ & In-house & wv & 1 & 148 & $0 \%$ & \\
\hline \multicolumn{12}{|c|}{ Pakistan $(n=32)$} \\
\hline Darwish [31] & $1983^{*}$ & Karachi & $\begin{array}{l}\text { Hospital; } \\
\text { patients }\end{array}$ & Conv. & $\mathrm{CF}$ & In-house & wv & 1 & 43 & $9.3 \%$ & \\
\hline \multirow[t]{2}{*}{ Akram [58] } & 1994 & Karachi & $\begin{array}{c}\text { Hospital; AFI } \\
\text { patients }(<1- \\
12)\end{array}$ & Conv. & $\begin{array}{l}\text { ELISA } \\
\text { IgM }\end{array}$ & In-house & wv & 1 & 92 & $9.8 \% * *$ & $\begin{array}{c}12 \%(3 / 25) \\
\text { additional } \\
\text { convalescent } \\
\text { sera were +; } \\
\text { observed } \\
\text { cross-reaction } \\
\text { to WNV }\end{array}$ \\
\hline & & & & Conv. & $\begin{array}{l}\text { ELISA } \\
\text { IgM }\end{array}$ & In-house & wv & 2 & Same & $14.6 \% * *$ & $\begin{array}{c}24 \%(6 / 25) \\
\text { additional } \\
\text { convalescent } \\
\text { sera were }+; \\
\text { observed } \\
\text { cross-reaction } \\
\text { to WNV }\end{array}$ \\
\hline Siddiqui [41] & $\begin{array}{c}1999- \\
2001\end{array}$ & Karachi & $\begin{array}{l}\text { Community; } \\
\text { AFI patients } \\
(<16)\end{array}$ & Conv. & $\begin{array}{l}\text { ELISA } \\
\text { IgM }\end{array}$ & Diag. Auto. & wv & $1-4$ & 341 & $15.8 \%$ & \\
\hline
\end{tabular}

(Continued) 
Table 3. (Continued)

\begin{tabular}{|c|c|c|c|c|c|c|c|c|c|c|c|}
\hline $\begin{array}{l}\text { Country, } \\
\text { Ref. }\end{array}$ & $\begin{array}{l}\text { Year(s) } \\
\text { of } \\
\text { study* }\end{array}$ & $\begin{array}{c}\text { City or } \\
\text { governorate }\end{array}$ & $\begin{array}{l}\text { Setting; } \\
\text { population } \\
\text { (age range, } \\
\text { years) }\end{array}$ & Sampling & $\begin{array}{l}\text { Assay } \\
\text { type }\end{array}$ & $\begin{array}{l}\text { Assay } \\
\text { make }^{\dagger}\end{array}$ & $\begin{array}{c}\text { Target } \\
\text { Protein }\end{array}$ & $\begin{array}{c}\text { Assay } \\
\text { serotype }\end{array}$ & $\begin{array}{c}\text { Sample } \\
\text { size }\end{array}$ & Prevalence & $\begin{array}{l}\text { Additional } \\
\text { testing \& } \\
\text { Comments }\end{array}$ \\
\hline Tariq [59] & 2003 & $\begin{array}{l}\text { Mangla, } \\
\text { Mirpur }\end{array}$ & $\begin{array}{l}\text { Community; } \\
\text { suspected } \\
\text { dengue }\end{array}$ & Conv. & $\begin{array}{l}\text { ELISA } \\
\text { IgM }\end{array}$ & In-house & $n / s$ & $n / s$ & 52 & $73 \%$ & \\
\hline Jamil [60] & 2005 & Karachi & $\begin{array}{l}\text { Hospitals; } \\
\text { suspected } \\
\text { dengue }\end{array}$ & Conv. & $\begin{array}{l}\text { ELISA } \\
\text { IgM }\end{array}$ & Chemicon & $n / s$ & $n / s$ & 106 & $36.8 \%$ & \\
\hline \multirow[t]{2}{*}{ Khan [61] } & 2006 & Karachi & $\begin{array}{c}\text { Hospital; } \\
\text { suspected } \\
\text { dengue }(2-72)\end{array}$ & Conv. & $\begin{array}{c}\text { ELISA } \\
\text { IgM }\end{array}$ & PanBio & Env & $1-4$ & 83 & $83.6 \%$ & \\
\hline & & & & Conv & $\begin{array}{l}\text { ELISA } \\
\text { IgM }\end{array}$ & Calbiotech & PA & $1-4$ & same & $50.7 \%$ & $\begin{array}{c}87.8 \%(73 / 83) \\
\text { were PCR+ for } \\
\text { DEN-2,3 only }\end{array}$ \\
\hline Khan [62] & 2006 & Karachi & $\begin{array}{l}\text { Hospital; } \\
\text { suspected } \\
\text { dengue }\end{array}$ & Conv. & ELISA & PanBio & Env & $1-4$ & 250 & $23.2 \%$ & $\begin{array}{c}53.6 \%(134 / \\
250) \text { were IgM } \\
+; 74 \%(185 / \\
250) \text { were } \\
\text { PCR+ for } \\
\text { DEN-2 or } 3\end{array}$ \\
\hline Koo [63] & $\begin{array}{c}2006- \\
11\end{array}$ & Multiple & $\begin{array}{l}\text { Clinic settings; } \\
\text { suspected } \\
\text { dengue }\end{array}$ & Conv. & PCR & In-house & & 2,3 & 200 & $47 \%$ & $\begin{array}{c}\text { none were } \\
\text { DEN-1 positive }\end{array}$ \\
\hline Khan [64] & $\begin{array}{c}2006- \\
07\end{array}$ & Hyderabad & $\begin{array}{c}\text { Hospital; } \\
\text { suspected } \\
\text { dengue (13- } \\
70)\end{array}$ & Conv. & $\begin{array}{l}\text { ELISA } \\
\text { IgM }\end{array}$ & In-house & $n / s$ & $n / s$ & 50 & $40 \%$ & \\
\hline Khan [65] & $\begin{array}{c}2006- \\
07\end{array}$ & Multiple & $\begin{array}{l}\text { Hospital; } \\
\text { suspected } \\
\text { dengue }\end{array}$ & Conv. & $\begin{array}{l}\text { ELISA } \\
\text { IgM }\end{array}$ & Calbiotech & PA & $1-4$ & 15,040 & $26.3 \%$ & \\
\hline Abbasi [66] & $\begin{array}{c}2007- \\
08\end{array}$ & Karachi & $\begin{array}{l}\text { Hospital; } \\
\text { suspected } \\
\text { dengue }\end{array}$ & Conv. & $\begin{array}{l}\text { ELISA } \\
\text { IgM }\end{array}$ & Commercial & $n / s$ & $n / s$ & 114 & $69.6 \%$ & \\
\hline Tahir [67] & 2008 & Lahore & $\begin{array}{l}\text { Hospital; } \\
\text { suspected } \\
\text { dengue }\end{array}$ & Conv. & $\begin{array}{l}\text { ICT } \\
(\operatorname{lgM})\end{array}$ & In-house & $n / s$ & $n / s$ & 3215 & $54.9 \%$ & \\
\hline Murad [68] & 2008 & Shangla & $\begin{array}{l}\text { Community; } \\
\text { suspected } \\
\text { dengue (1-80) }\end{array}$ & Conv. & $\begin{array}{l}\text { ELISA } \\
\text { IgM }\end{array}$ & $n / s$ & $n / s$ & $n / s$ & 70 & $17.1 \%$ & \\
\hline \multirow[t]{2}{*}{$\begin{array}{l}\text { Mahmood } \\
\text { [69] }\end{array}$} & 2008 & Lahore & $\begin{array}{c}\text { Hospital; } \\
\text { suspected } \\
\text { dengue } \\
\text { secondary } \\
\text { infection (age } \\
1-80 \text { ) }\end{array}$ & Conv. & ELISA & NovaLisa & Env & $1-4$ & 200 & $39.5 \%$ & \\
\hline & & & $\begin{array}{l}\text { Hospital; } \\
\text { suspected } \\
\text { dengue } \\
\text { primary } \\
\text { infection (age } \\
\text { 1-80) }\end{array}$ & Conv. & $\begin{array}{l}\text { ELISA } \\
\text { IgM }\end{array}$ & DRG & $n / s$ & 2 & 341 & $48.7 \%$ & \\
\hline Kidwai [70] & $\begin{array}{c}2008- \\
09\end{array}$ & Karachi & $\begin{array}{c}\text { Hospital; } \\
\text { suspected } \\
\text { dengue }(>13)\end{array}$ & Conv. & $\begin{array}{l}\text { ICT } \\
(\operatorname{lgG})\end{array}$ & In-house & wV & $1-4$ & 599 & $83.2 \%$ & $\begin{array}{c}41.9 \%(251 / \\
599) \text { were } \operatorname{lgM} \\
+\end{array}$ \\
\hline
\end{tabular}

(Continued) 
Table 3. (Continued)

\begin{tabular}{|c|c|c|c|c|c|c|c|c|c|c|c|}
\hline $\begin{array}{l}\text { Country, } \\
\text { Ref. }\end{array}$ & $\begin{array}{l}\text { Year(s) } \\
\text { of } \\
\text { study* }\end{array}$ & $\begin{array}{c}\text { City or } \\
\text { governorate }\end{array}$ & $\begin{array}{c}\text { Setting; } \\
\text { population } \\
\text { (age range, } \\
\text { years) }\end{array}$ & Sampling & $\begin{array}{l}\text { Assay } \\
\text { type }\end{array}$ & $\begin{array}{l}\text { Assay } \\
\text { make }^{\dagger}\end{array}$ & $\begin{array}{l}\text { Target } \\
\text { Protein }\end{array}$ & \begin{tabular}{|c|} 
Assay \\
serotype
\end{tabular} & $\begin{array}{l}\text { Sample } \\
\text { size }\end{array}$ & Prevalence & $\begin{array}{l}\text { Additional } \\
\text { testing \& } \\
\text { Comments }\end{array}$ \\
\hline Zafar [71] & 2009 & Rawalpindi & $\begin{array}{c}\text { rural } \\
\text { communities; } \\
\text { adults without } \\
\text { history of } \\
\text { flavivirus } \\
\text { vaccination } \\
(>18)\end{array}$ & StRS & ELISA & Omega & $\begin{array}{l}\text { PA } \\
\text { (DEN- } \\
2)\end{array}$ & $1-4$ & 96 & $19.8 \%$ & \\
\hline Zafar [72] & 2009 & Rawalpindi & $\begin{array}{l}\text { Community; } \\
\text { general pop. }\end{array}$ & Conv. & ELISA & $\begin{array}{l}\text { Omega, } \\
\text { Vircell }\end{array}$ & $\begin{array}{l}\text { PA } \\
\text { (DEN- } \\
2 \text { ) }\end{array}$ & $1-4$ & 244 & $28.8 \%$ & \\
\hline Qureshi [73] & $\begin{array}{c}2010- \\
12\end{array}$ & Karachi & $\begin{array}{l}\text { Hospital; } \\
\text { suspected } \\
\text { dengue }\end{array}$ & Conv. & $\begin{array}{l}\text { ICT } \\
\text { (IgM) }\end{array}$ & In-house & $n / s$ & $n / s$ & 162 & $9.9 \%$ & \\
\hline Khan [74] & 2010 & Punjab & $\begin{array}{c}\text { Hospital; } \\
\text { suspected } \\
\text { dengue }(4-60)\end{array}$ & Conv. & $\begin{array}{l}\text { ELISA } \\
\text { IgM }\end{array}$ & $n / s$ & $n / s$ & $n / s$ & 125 & $54.4 \%$ & \\
\hline Hasan [75] & 2010 & Karachi & $\begin{array}{c}\text { Hospital; } \\
\text { suspected } \\
\text { dengue }(>12)\end{array}$ & Conv. & $\begin{array}{l}\text { ELISA } \\
\text { IgM }\end{array}$ & $n / s$ & $n / s$ & $n / s$ & 259 & $34.8 \%$ & \\
\hline Umar [76] & 2010 & Rawalpindi & $\begin{array}{l}\text { Hospital; } \\
\text { suspected } \\
\text { dengue }\end{array}$ & Conv. & $\begin{array}{l}\text { ELISA } \\
\text { IgM }\end{array}$ & $n / s$ & $\mathrm{n} / \mathrm{s}$ & $n / s$ & 500 & $6.8 \%$ & \\
\hline Jameel [77] & 2010 & Lahore & $\begin{array}{l}\text { Hospital; } \\
\text { suspected } \\
\text { dengue }\end{array}$ & Conv. & $\begin{array}{l}\text { ELISA } \\
\text { IgM }\end{array}$ & In-house & $n / s$ & $n / s$ & 341 & $48.7 \%$ & \\
\hline Naeem [78] & 2011 & Lahore & $\begin{array}{c}\text { Hospital; } \\
\text { suspected } \\
\text { dengue (1-10 } \\
+)\end{array}$ & Conv. & $\begin{array}{l}\text { ELISA } \\
\text { IgM }\end{array}$ & $n / s$ & $n / s$ & $n / s$ & 79 & $25.3 \%$ & \\
\hline Ahmed [79] & 2011 & Lahore & $\begin{array}{c}\text { Hospital; } \\
\text { suspected } \\
\text { dengue (13- } \\
\text { 81) }\end{array}$ & Conv. & $\begin{array}{l}\text { ELISA } \\
\text { IgM }\end{array}$ & $n / s$ & $n / s$ & $n / s$ & 640 & $43.9 \%$ & \\
\hline ljaz [80] & 2011 & Lahore & $\begin{array}{c}\text { Hospital; } \\
\text { suspected } \\
\text { dengue }(<15- \\
60+)\end{array}$ & Conv. & ELISA & $\mathrm{n} / \mathrm{s}$ & $n / s$ & $1-4$ & 5,274 & $49 \%$ & \\
\hline Rashid [81] & 2011 & Lahore & $\begin{array}{c}\text { Hospital; } \\
\text { suspected } \\
\text { dengue }(<18)\end{array}$ & Conv. & ELISA & $n / s$ & $n / s$ & $n / s$ & 254 & $36.6 \%$ & $\begin{array}{c}53.9 \%(137 / \\
254) \text { were IgM } \\
+\end{array}$ \\
\hline Khan [82] & 2011 & Lahore & $\begin{array}{c}\text { Hospital; } \\
\text { suspected } \\
\text { dengue (5-50 } \\
+)\end{array}$ & Conv. & ELISA & In-house & wv & $1-4$ & 50 & $72 \%$ & $\begin{array}{c}30 \%(30 / 50) \\
\text { were IgM+; } \\
66 \%(33 / 50) \\
\text { were PCR+ for } \\
\text { DEN-1,2; 60\% } \\
\text { (30/50) were } \\
\text { cell culture+ }\end{array}$ \\
\hline Hasan [83] & $\begin{array}{c}2007- \\
13\end{array}$ & Multiple & $\begin{array}{c}\text { Hospitals; } \\
\text { suspected } \\
\text { Crimean- } \\
\text { Congo } \\
\text { Hemorrhagic } \\
\text { Fever }\end{array}$ & Conv. & $\begin{array}{l}\text { ELISA } \\
\text { IgM }\end{array}$ & PanBio & Env & $1-4$ & 168 & $33.9 \%$ & $\begin{array}{c}2.3 \%(4 / 168) \\
\text { were PCR+ }\end{array}$ \\
\hline
\end{tabular}

(Continued) 
Table 3. (Continued)

\begin{tabular}{|c|c|c|c|c|c|c|c|c|c|c|c|}
\hline $\begin{array}{l}\text { Country, } \\
\text { Ref. }\end{array}$ & $\begin{array}{l}\text { Year(s) } \\
\text { of } \\
\text { study* }\end{array}$ & $\begin{array}{c}\text { City or } \\
\text { governorate }\end{array}$ & $\begin{array}{c}\text { Setting; } \\
\text { population } \\
\text { (age range, } \\
\text { years) }\end{array}$ & Sampling & $\begin{array}{c}\text { Assay } \\
\text { type }\end{array}$ & $\begin{array}{l}\text { Assay } \\
\text { make }^{\dagger}\end{array}$ & \begin{tabular}{|c|} 
Target \\
Protein
\end{tabular} & \begin{tabular}{|c|} 
Assay \\
serotype
\end{tabular} & $\begin{array}{c}\text { Sample } \\
\text { size }\end{array}$ & Prevalence & $\begin{array}{l}\text { Additional } \\
\text { testing \& } \\
\text { Comments }\end{array}$ \\
\hline Ali [84] & 2011 & $\begin{array}{c}\text { Khyber } \\
\text { Pakhtunkhwa }\end{array}$ & $\begin{array}{c}\text { Clinical } \\
\text { settings; } \\
\text { suspected } \\
\text { dengue }(<10 \text { to } \\
>51)\end{array}$ & Conv. & ELISA & Diag. Auto. & wv & $1-4$ & 612 & $20.2 \%$ & $\begin{array}{c}31.9 \%(195 / \\
612) \text { were IgM } \\
+\end{array}$ \\
\hline Hisam [85] & 2012 & Rawalpindi & $\begin{array}{c}\text { Military } \\
\text { Hospital; AFI } \\
\text { patients }\end{array}$ & PS & $\begin{array}{c}\text { ELISA } \\
\operatorname{IgM}\end{array}$ & $n / s$ & $n / s$ & $n / s$ & 500 & $3.2 \%$ & \\
\hline Assir [86] & 2012 & Lahore & $\begin{array}{c}\text { Hospital; } \\
\text { suspected } \\
\text { dengue (12- } \\
90)\end{array}$ & Conv. & $\begin{array}{c}\text { ELISA } \\
\text { IgM }\end{array}$ & $\mathrm{GmbH}$ & wv & $1-4$ & 85 & $43.5 \%$ & $\begin{array}{c}20 \%(3 / 15) \\
\text { were PCR } \\
+ \text { for DEN-2 }\end{array}$ \\
\hline \multicolumn{12}{|c|}{ Saudi Arabia $(n=11)$} \\
\hline Fakeeh [87] & $\begin{array}{c}1994- \\
99\end{array}$ & Jeddah & $\begin{array}{l}\text { Hospitals; } \\
\text { suspected } \\
\text { dengue (1- } \\
>50)\end{array}$ & Conv. & $\begin{array}{l}\text { IIFA, } \\
\text { HI }\end{array}$ & In-house & wv & 1,2 & 985 & $31.9 \%$ & $\begin{array}{c}16.2 \%(160 / \\
985) \text { were } \\
\text { ELISA IgM+; } \\
21 \%(207 / 985) \\
\text { were PCR+ } \\
\text { (DEN-1,2,3) }\end{array}$ \\
\hline Fakeeh [88] & $\begin{array}{c}1994- \\
2002\end{array}$ & Jeddah & $\begin{array}{l}\text { Hospitals; } \\
\text { suspected } \\
\text { dengue }\end{array}$ & Conv. & IFA, HI & In-house & wv & $1,2,3$ & 1020 & $50.5 \%$ & $\begin{array}{c}10.8 \%(110 / \\
1020) \text { were } \\
\text { ELISA IgM+; } \\
20.5 \%(209 / \\
1020) \text { were } \\
\text { PCR+ (DEN- } \\
1,2,3)\end{array}$ \\
\hline Khan [89] & 2004 & Makkah & $\begin{array}{c}\text { Hospital; } \\
\text { suspected } \\
\text { dengue }(6-94)\end{array}$ & & ELISA & PanBio & Env & $1-4$ & 136 & $32.4 \%$ & $\begin{array}{c}58.8 \%(80 / \\
136) \text { were IgM } \\
+; 28.1 \%(27 / \\
96) \text { were PCR } \\
+(\text { DEN-2,3) }\end{array}$ \\
\hline Ayyub [90] & $\begin{array}{c}2004- \\
05\end{array}$ & Jeddah & $\begin{array}{c}\text { Hospital; } \\
\text { suspected } \\
\text { dengue }(2-60)\end{array}$ & Conv. & $\begin{array}{c}\text { ELISA } \\
\operatorname{IgM}\end{array}$ & $n / s$ & $n / s$ & $n / s$ & 80 & $48.8 \%$ & \\
\hline Shahin [91] & $\begin{array}{c}2006- \\
08\end{array}$ & Makkah & $\begin{array}{l}\text { Hospital; } \\
\text { suspected } \\
\text { dengue }\end{array}$ & Conv. & $\begin{array}{l}\text { ELISA } \\
\text { IgM } \\
\text { and/or } \\
\text { PCR }\end{array}$ & $n / s$ & $n / s$ & $n / s$ & 159 & $100 \%$ & \\
\hline Said [92] & 2006 & Jeddah & $\begin{array}{c}\text { Hospital; } \\
\text { suspected } \\
\text { dengue }(2-71)\end{array}$ & Conv. & $\begin{array}{c}\text { ELISA } \\
\text { IgM }\end{array}$ & In-house & $n / s$ & $n / s$ & 525 & $19.2 \%$ & $\begin{array}{l}\text { \% includes } \\
\text { paired serum } \\
\text { sample }\end{array}$ \\
\hline Memish [93] & 2010 & Multiple & Military; adults & Conv. & ELISA & PanBio & Env & $1-4$ & 1024 & $0.1 \%$ & $\begin{array}{c}0 \% \text { of } \operatorname{lgG} \\
+ \text { were } \operatorname{lgM}+\end{array}$ \\
\hline Gamil [94] & $\begin{array}{c}2010- \\
11\end{array}$ & Jeddah & $\begin{array}{c}\text { Hospitals; } \\
\text { suspected } \\
\text { dengue }(3-56)\end{array}$ & Conv. & $n / s$ & $n / s$ & $n / s$ & $n / s$ & 553 & $47.7 \%$ & \\
\hline \multirow[t]{2}{*}{$\begin{array}{l}\text { Al-Azraqi } \\
\text { [95] }\end{array}$} & 2013 & Jizan & $\begin{array}{l}\text { Clinics; clinic } \\
\text { attendants (1- } \\
60+)\end{array}$ & SRS & ELISA & Focus & wv & $1-4$ & 268 & $26.5 \%$ & \\
\hline & & Aseer & $\begin{array}{l}\text { Clinics; clinic } \\
\text { attendants (1- } \\
60+)\end{array}$ & SRS & ELISA & Focus & wv & $1-4$ & 697 & $33.7 \%$ & \\
\hline
\end{tabular}

(Continued) 
Table 3. (Continued)

\begin{tabular}{|c|c|c|c|c|c|c|c|c|c|c|c|}
\hline $\begin{array}{l}\text { Country, } \\
\text { Ref. }\end{array}$ & $\begin{array}{l}\text { Year(s) } \\
\text { of } \\
\text { study* }\end{array}$ & $\begin{array}{c}\text { City or } \\
\text { governorate }\end{array}$ & $\begin{array}{c}\text { Setting; } \\
\text { population } \\
\text { (age range, } \\
\text { years) }\end{array}$ & Sampling & $\begin{array}{l}\text { Assay } \\
\text { type }\end{array}$ & $\begin{array}{l}\text { Assay } \\
\text { make }^{\dagger}\end{array}$ & $\begin{array}{c}\text { Target } \\
\text { Protein }\end{array}$ & $\begin{array}{l}\text { Assay } \\
\text { serotype }\end{array}$ & $\begin{array}{l}\text { Sample } \\
\text { size }\end{array}$ & Prevalence & $\begin{array}{l}\text { Additional } \\
\text { testing\& } \\
\text { Comments }\end{array}$ \\
\hline Ashshi [96] & 2014 & Mecca & $\begin{array}{l}\text { blood donation } \\
\text { center; adults }\end{array}$ & Conv. & ELISA & PanBio & Env & $1-4$ & 100 & $7 \%$ & $\begin{array}{c}6 \%(6 / 100) \\
\text { were IgM+;1\% } \\
(1 / 100) \text { were } \\
\text { NS1+ }\end{array}$ \\
\hline \multicolumn{12}{|c|}{ Somalia $(n=7)$} \\
\hline Botros [97] & 1987 & Hargeysa & $\begin{array}{l}\text { Refugee } \\
\text { camp; AFI } \\
\text { patients }\end{array}$ & Conv. & ELISA & In-house & wv & 2 & 38 & $60.7 \%$ & $\begin{array}{c}\text { acute and } \\
\text { convalescent } \\
\text { samples; } \\
39.4 \%(15 / 38) \\
\text { were IFA+; } \\
37.9 \%(11 / 29) \\
\text { were HI+; } \\
14.2 \%(4 / 28) \\
\text { were ELISA } \\
\text { IgM+ }\end{array}$ \\
\hline $\begin{array}{l}\text { Kanesa- } \\
\text { thasan [98] }\end{array}$ & 1993 & $n / s$ & $\begin{array}{l}\text { Military base; } \\
\text { AFI soldiers }\end{array}$ & Conv. & $\begin{array}{l}\text { ELISA } \\
\text { IgM } \\
\text { and/or } \\
\text { HI }\end{array}$ & $n / s$ & $n / s$ & $n / s$ & 84 & $17.8 \%$ & $\begin{array}{c}93 \%(14 / 15) \\
\text { were cell } \\
\text { culture }+ \\
\text { (DEN-2 and } 3 \\
\text { only) }\end{array}$ \\
\hline \multirow[t]{2}{*}{ Sharp [99] } & $\begin{array}{c}1992- \\
93\end{array}$ & Mogadishu & $\begin{array}{c}\text { Military } \\
\text { Hospital; AFI } \\
\text { patients } \\
\text { (soldiers) }\end{array}$ & Conv. & $\begin{array}{l}\text { ELISA } \\
\text { IgM }\end{array}$ & In-house & wv & $1-4$ & 129 & $34.9 \%$ & $\begin{array}{c}\text { 40.6\% (39/96) } \\
\text { were cell } \\
\text { culture positive } \\
\text { for DEN-2; } 2 \% \\
(2 / 96) \text { were } \\
\text { cell culture } \\
\text { positive for } \\
\text { DEN-3 }\end{array}$ \\
\hline & & Baardera & $\begin{array}{l}\text { Military; adults } \\
\quad(19-25)\end{array}$ & Conv. & $\begin{array}{l}\text { ELISA } \\
\text { IgM }\end{array}$ & In-house & wv & $1-4$ & 494 & $7.7 \% * *$ & $\begin{array}{c}\text { observed } \\
\text { cross-reaction } \\
\text { with WNV }\end{array}$ \\
\hline \multirow[t]{2}{*}{ Nur [100] } & 1995 & Mogadishu & $\begin{array}{c}\text { Hospital; } \\
\text { children }(<1 \\
\text { to }>2 \text { years of } \\
\text { age })\end{array}$ & CC. & $\begin{array}{l}\text { ELISA } \\
\text { IgM }\end{array}$ & Progen & wv & 2 & 23 & $0 \%$ & \\
\hline & & & $\begin{array}{l}\text { Hospital; AFI } \\
\text { patients with / } \\
\text { without rash } \\
(<1 \text { to }>2 \\
\text { years of age })\end{array}$ & CC. & $\begin{array}{l}\text { ELISA } \\
\text { IgM }\end{array}$ & Progen & wv & 2 & 46 & $0 \%$ & \\
\hline $\begin{array}{l}\text { Kyobe Bosa } \\
\text { [101] }\end{array}$ & 2011 & Mogadishu & $\begin{array}{c}\text { Hospitals; AFI } \\
\text { patients (20- } \\
49)\end{array}$ & Conv. & $\begin{array}{l}\text { ELISA } \\
\text { IgM }\end{array}$ & $n / s$ & $n / s$ & $1,2,3$ & 134 & $80 \%$ & $\begin{array}{c}62 \%(83 / 134) \\
\text { were PCR+ }\end{array}$ \\
\hline \multicolumn{12}{|c|}{ Sudan $(n=16)$} \\
\hline Omer [36] & 1976 & Gezira & $\begin{array}{c}\text { Rural } \\
\text { community; } \\
\text { general pop. } \\
(5-40+)\end{array}$ & Conv. & $\mathrm{HI}$ & In-house & wv & 2 & 109 & $27.5 \%$ & $\begin{array}{c}17.4 \%(19 / \\
109) \text { were VNT } \\
+\end{array}$ \\
\hline $\begin{array}{l}\text { Hyams } \\
\text { [102] }\end{array}$ & 1984 & Port Sudan & $\begin{array}{l}\text { Hospital; AFI } \\
\text { patients (12- } \\
70)\end{array}$ & Conv. & $\mathrm{HI}$ & In-house & wV & $n / s$ & 100 & $3 \%$ & $\begin{array}{c}14.8 \%(8 / 54) \\
\text { were } \\
\text { convalescent } \\
+; 1 \%(1 / 100) \\
\text { DEN-1 cell } \\
\text { culture +; } 17 \% \\
\text { (17/100) DEN- } \\
2 \text { cell culture + }\end{array}$ \\
\hline
\end{tabular}

(Continued) 
Table 3. (Continued)

\begin{tabular}{|c|c|c|c|c|c|c|c|c|c|c|c|}
\hline $\begin{array}{l}\text { Country, } \\
\text { Ref. }\end{array}$ & $\begin{array}{l}\text { Year(s) } \\
\text { of } \\
\text { study* }\end{array}$ & $\begin{array}{c}\text { City or } \\
\text { governorate }\end{array}$ & $\begin{array}{c}\text { Setting; } \\
\text { population } \\
\text { (age range, } \\
\text { years) }\end{array}$ & Sampling & $\begin{array}{l}\text { Assay } \\
\text { type }\end{array}$ & $\begin{array}{l}\text { Assay } \\
\text { make }^{\dagger}\end{array}$ & $\begin{array}{l}\text { Target } \\
\text { Protein }\end{array}$ & $\begin{array}{c}\text { Assay } \\
\text { serotype }\end{array}$ & $\begin{array}{l}\text { Sample } \\
\text { size }\end{array}$ & Prevalence & $\begin{array}{l}\text { Additional } \\
\text { testing \& } \\
\text { Comments }\end{array}$ \\
\hline $\begin{array}{l}\text { Woodruff } \\
\text { [103] }\end{array}$ & 1986 & Juba & $\begin{array}{c}\text { Hospital; } \\
\text { patients with } \\
\text { history of fever } \\
\text { within past } 6 \\
\text { months and } \\
\text { AFI patients } \\
(1-85)\end{array}$ & Conv. & $\mathrm{HI}$ & In-house & $n / s$ & $n / s$ & 130 & $40.0 \% * *$ & $\begin{array}{c}\text { represents } \\
\text { single virus } \\
\text { activity not } \\
\text { cross-reactive } \\
\text { to multiple } \\
\text { flaviviruses } \\
\text { tested }\end{array}$ \\
\hline \multirow[t]{2}{*}{$\begin{array}{l}\text { McCarthy } \\
{[104]}\end{array}$} & 1988 & Khartoum & $\begin{array}{c}\text { Clinical } \\
\text { setting; non- } \\
\text { AFI patients }\end{array}$ & $\mathrm{CC}$ & ELISA & In-house & wv & 2 & 100 & $49 \%$ & $0 \%$ were lgM+ \\
\hline & & & $\begin{array}{c}\text { Clinical } \\
\text { setting; AFI } \\
\text { patients (1-89) }\end{array}$ & $\mathrm{CC}$ & ELISA & In-house & wv & 2 & 196 & $48 \% * *$ & $\begin{array}{c}0 \% \text { were lgM+; } \\
\text { possible cross- } \\
\text { reaction to } \\
\text { WNV }\end{array}$ \\
\hline Watts [18] & 1989 & $\begin{array}{l}\text { Northern } \\
\text { Province }\end{array}$ & $\begin{array}{c}\text { Clinical } \\
\text { setting; AFI } \\
\text { patients (11- } \\
70)\end{array}$ & Conv. & ELISA & In-house & $n / s$ & 2 & 185 & $24.0 \% * *$ & $\begin{array}{c}\text { possible cross- } \\
\text { reactions to } \\
\text { multiple } \\
\text { flaviviruses }\end{array}$ \\
\hline $\begin{array}{l}\text { Ibrahim } \\
\text { [105] }\end{array}$ & $\begin{array}{c}1997- \\
99\end{array}$ & Khartoum & $\begin{array}{l}\text { Clinical } \\
\text { setting: } \\
\text { suspected } \\
\text { measles }\end{array}$ & Conv. & $\begin{array}{l}\text { ELISA } \\
\text { IgM }\end{array}$ & MRL Diag. & $n / s$ & $n / s$ & 188 & $3.2 \%$ & \\
\hline Malik [106] & $\begin{array}{c}2004- \\
05\end{array}$ & Port Sudan & $\begin{array}{c}\text { Hospitals; } \\
\text { suspected } \\
\text { dengue }(<1- \\
15)\end{array}$ & Conv. & $\begin{array}{l}\text { ELISA } \\
\text { IgM }\end{array}$ & PanBio & Env & $1-4$ & 40 & $90.0 \%$ & $\begin{array}{c}39 \%(9 / 23) \\
\text { were PCR+ } \\
\text { (DEN-3) }\end{array}$ \\
\hline Gould [107] & 2005 & $\begin{array}{l}\text { South } \\
\text { Kordofan }\end{array}$ & $\begin{array}{c}\text { Clinical } \\
\text { setting; } \\
\text { suspected YF } \\
\text { patients } \\
(n=3), \text { severe } \\
\text { illness }(n=8), \\
\text { AFI patients } \\
(n=7), \text { healthy } \\
(n=16)\end{array}$ & Conv. & $\begin{array}{l}\text { ELISA } \\
\text { IgM }\end{array}$ & In-house & wV & $n / s$ & 34 & $5.9 \% * *$ & $\begin{array}{c}\text { observed } \\
\text { cross-reaction } \\
\text { with YFV, } \\
\text { WNV }\end{array}$ \\
\hline Farnon [38] & 2005 & Kortalla & $\begin{array}{c}\text { Community; } \\
\text { general pop., } \\
\text { YF vaccinated } \\
(0-44+)\end{array}$ & SSCS & ELISA & In-house & wV & $1-4$ & 87 & $1.1 \% * *$ & $\begin{array}{c}\text { observed } \\
\text { cross-reaction } \\
\text { in YF vaccine } \\
\text { recipient; } 0 \% \\
\text { were IgM+; } \\
52 \%(45 / 87) \\
\text { were VNT+ for } \\
\text { DENV and } \\
\text { YFV }\end{array}$ \\
\hline $\begin{array}{l}\text { Seidahmed } \\
\text { [39] }\end{array}$ & $\begin{array}{c}2008- \\
09\end{array}$ & $\begin{array}{l}\text { Port Sudan } \\
\text { City }\end{array}$ & $\begin{array}{c}\text { Urban } \\
\text { community; } \\
\text { individuals } \\
\text { from houses } \\
\text { with DENV- } \\
\text { carrying } \\
\text { mosquitoes } \\
(<1-80)\end{array}$ & RSS & $\begin{array}{l}\text { ELISA } \\
\text { IgM }\end{array}$ & PanBio & Env & $1-4$ & 791 & $5.2 \%$ & \\
\hline Adam [108] & $\begin{array}{c}2008- \\
09\end{array}$ & $\begin{array}{l}\text { Port Sudan } \\
\text { City }\end{array}$ & $\begin{array}{c}\text { Hospitals; } \\
\text { pregnant } \\
\text { women with } \\
\text { deliveries }\end{array}$ & $\begin{array}{l}\text { Ret. } \\
\text { cohort }\end{array}$ & $\begin{array}{l}\text { ELISA } \\
\text { IgM }\end{array}$ & $n / s$ & $n / s$ & $1-4$ & 10,820 & $0.7 \%$ & \\
\hline
\end{tabular}

(Continued) 
Table 3. (Continued)

\begin{tabular}{|c|c|c|c|c|c|c|c|c|c|c|c|}
\hline $\begin{array}{l}\text { Country, } \\
\text { Ref. }\end{array}$ & $\begin{array}{l}\text { Year(s) } \\
\text { of } \\
\text { study* }\end{array}$ & $\begin{array}{c}\text { City or } \\
\text { governorate }\end{array}$ & $\begin{array}{l}\text { Setting; } \\
\text { population } \\
\text { (age range, } \\
\text { years) }\end{array}$ & Sampling & $\begin{array}{l}\text { Assay } \\
\text { type }\end{array}$ & $\begin{array}{l}\text { Assay } \\
\text { make }^{\dagger}\end{array}$ & $\begin{array}{l}\text { Target } \\
\text { Protein }\end{array}$ & $\begin{array}{c}\text { Assay } \\
\text { serotype }\end{array}$ & $\begin{array}{c}\text { Sample } \\
\text { size }\end{array}$ & Prevalence & $\begin{array}{l}\text { Additional } \\
\text { testing \& } \\
\text { Comments }\end{array}$ \\
\hline Himatt [109] & 2011 & Kassala state & $\begin{array}{l}\text { Community; } \\
\text { general pop. } \\
(5-75+)\end{array}$ & MSCS & ELISA & PanBio & Env & $1-4$ & 489 & $9.4 \%$ & $\begin{array}{c}0.6 \%(3 / 489) \\
\text { were lgM+ }\end{array}$ \\
\hline $\begin{array}{l}\text { Abdalla } \\
{[110]}\end{array}$ & 2012 & Kassala State & $\begin{array}{l}\text { Hospital; AFI } \\
\text { patients with } \\
\text { suspected } \\
\text { measles (2- } \\
65 \text { ) }\end{array}$ & Conv. & ELISA & PanBio & Env & $1-4$ & 60 & $11.7 \%$ & \\
\hline Elduma [15] & 2012 & Port Sudan & $\begin{array}{c}\text { Hospital; } \\
\text { pregnant } \\
\text { women with } \\
\text { AFI }\end{array}$ & Conv. & ELISA & Commercial & $\mathrm{n} / \mathrm{s}$ & $\mathrm{n} / \mathrm{s}$ & 39 & $12.8 \%$ & $\begin{array}{c}2.6 \%(1 / 39) \\
\text { were } \operatorname{lgM}+\text { and } \\
\text { PCR+ }\end{array}$ \\
\hline $\begin{array}{l}\text { Soghaier } \\
\text { [111] }\end{array}$ & 2014 & $\begin{array}{l}\text { South } \\
\text { Kordofan }\end{array}$ & $\begin{array}{l}\text { Urban and } \\
\text { rural } \\
\text { communities; } \\
\text { general pop. } \\
(15-60)\end{array}$ & MSCS & ELISA & PanBio & Env & $1-4$ & 600 & $27.7 \%$ & $\begin{array}{l}77 \% \text { of study } \\
\text { population } \\
\text { were YFV } \\
\text { vaccinated }\end{array}$ \\
\hline \multicolumn{12}{|l|}{ Turkey $(n=6)$} \\
\hline Ari [34] & 1971 & Izmir & $\begin{array}{l}\text { Community } \\
\text { and clinic; } \\
\text { general pop. }\end{array}$ & Conv. & $\mathrm{HI}$ & In-house & wv & 2 & 270 & $0 \%$ & \\
\hline \multirow[t]{3}{*}{ Radda [112] } & $1973^{*}$ & Izmir & $\begin{array}{l}\mathrm{n} / \mathrm{s} \text {; general } \\
\text { pop. }\end{array}$ & Conv. & $\mathrm{HI}$ & In-house & wv & 2 & 270 & $0.3 \% * *$ & $\begin{array}{c}\text { observed } \\
\text { cross-reaction } \\
\text { with WNV }\end{array}$ \\
\hline & & Istanbul & $\begin{array}{c}\mathrm{n} / \mathrm{s} \text {; general } \\
\text { pop. }\end{array}$ & Conv. & $\mathrm{HI}$ & In-house & wv & 2 & 90 & $0 \%$ & \\
\hline & & Ankara & $\begin{array}{l}\mathrm{n} / \mathrm{s} \text {; general } \\
\text { pop. }\end{array}$ & Conv. & $\mathrm{HI}$ & In-house & wv & 2 & 95 & $0 \%$ & \\
\hline $\begin{array}{l}\text { Ergunay } \\
\text { [113] }\end{array}$ & 2010 & $\begin{array}{l}\text { Ankara, } \\
\text { Konya, } \\
\text { Eskisehir, } \\
\text { Zonguldak }\end{array}$ & $\begin{array}{l}\text { blood donation } \\
\text { center; blood } \\
\text { donors }\end{array}$ & Conv. & ELISA & Eurolmmun & wv & $1-4$ & 2435 & $0.9 \%$ & $\begin{array}{c}14.2 \%(3 / 21) \\
\text { of } \operatorname{lgG}+\text { were } \\
\text { IIFT+ for DEN- } \\
2 ; 9.5 \%(2 / 21) \\
\text { of } \lg G+\text { were } \\
\operatorname{lgM}+\end{array}$ \\
\hline $\begin{array}{l}\text { Tezcan } \\
{[114]}\end{array}$ & $\begin{array}{c}2010- \\
11\end{array}$ & Mersin & $\begin{array}{l}\text { blood donation } \\
\text { center; blood } \\
\text { donors }\end{array}$ & Conv. & ELISA & Vircell & wv & $1-4$ & 920 & $16.6 \%$ & $\begin{array}{c}0.9 \%(8 / 920) \\
\text { were } \operatorname{lgM}+; 0 \% \\
\text { were } \mathrm{NS} 1+\end{array}$ \\
\hline \multicolumn{12}{|l|}{ Yemen $(n=5)$} \\
\hline $\begin{array}{l}\text { Bin Ghouth } \\
\text { [115] }\end{array}$ & 2011 & Hadramout & $\begin{array}{c}\text { Hospital; } \\
\text { suspected } \\
\text { dengue }(<5 \text { to } \\
55+)\end{array}$ & Conv. & ELISA & PanBio & Env & $1-4$ & 982 & $50.6 \%$ & $\begin{array}{c}64.1 \%(630 / \\
982) \text { lgM+; } \\
86.2 \%(163 / \\
189) \text { PCR+ for } \\
\text { DEN-3 }\end{array}$ \\
\hline Malik [116] & $\begin{array}{l}2010- \\
11\end{array}$ & Al-Hudaydah & $\begin{array}{c}\text { Clinical } \\
\text { setting; AFI } \\
\text { patients (0-45 } \\
+)\end{array}$ & Conv. & ELISA & PanBio & Env & $1-4$ & 136 & $87.5 \%$ & $\begin{array}{c}8.1 \%(11 / 136) \\
\text { were lgM+ }\end{array}$ \\
\hline $\begin{array}{l}\text { Madani } \\
{[117]}\end{array}$ & 2010 & Hadramout & $\begin{array}{c}\text { Clinical } \\
\text { settings; } \\
\text { suspected viral } \\
\text { hemorrhagic } \\
\text { fever (3-75) }\end{array}$ & Conv. & ELISA & PanBio & Env & $1-4$ & 207 & $48.3 \%$ & $\begin{array}{c}78.7 \%(163 / \\
207) \text { IgM+; } \\
46.9 \%(97 / \\
207) \text { NS1+; } \\
0.09 \%(2 / 207) \\
\text { PCR+ for } \\
\text { DEN-1,2 }\end{array}$ \\
\hline
\end{tabular}

(Continued) 
Table 3. (Continued)

\begin{tabular}{|c|c|c|c|c|c|c|c|c|c|c|c|}
\hline $\begin{array}{l}\text { Country, } \\
\text { Ref. }\end{array}$ & $\begin{array}{l}\text { Year(s) } \\
\text { of } \\
\text { study* }\end{array}$ & $\begin{array}{c}\text { City or } \\
\text { governorate }\end{array}$ & $\begin{array}{c}\text { Setting; } \\
\text { population } \\
\text { (age range, } \\
\text { years) }\end{array}$ & Sampling & $\begin{array}{c}\text { Assay } \\
\text { type }\end{array}$ & $\begin{array}{l}\text { Assay } \\
\text { make }^{\dagger}\end{array}$ & $\begin{array}{c}\text { Target } \\
\text { Protein }\end{array}$ & $\begin{array}{l}\text { Assay } \\
\text { serotype }\end{array}$ & $\begin{array}{c}\text { Sample } \\
\text { size }\end{array}$ & Prevalence & $\begin{array}{l}\text { Additional } \\
\text { testing \& } \\
\text { Comments }\end{array}$ \\
\hline Rezza [118] & 2012 & Al Hudaydah & $\begin{array}{l}\text { Hospitals; AFI } \\
\text { patients with } \\
\text { dengue-like } \\
\text { illness }(1-60)\end{array}$ & CS & ELISA & NovaLisa & Env & $1-4$ & 400 & $72.5 \%$ & $\begin{array}{c}18 \%(72 / 400) \\
\text { IgM+; } 13.8 \% \\
(55 / 400) \text { PCR } \\
+ \text { for DEN-1,2 }\end{array}$ \\
\hline $\begin{array}{l}\text { Qassem } \\
\text { [119] }\end{array}$ & 2013 & Hadramout & $\begin{array}{c}\text { Clinical } \\
\text { setting; } \\
\text { suspected } \\
\text { dengue and/or } \\
\text { west nile } \\
\text { infection }\end{array}$ & Conv. & $\begin{array}{c}\text { ELISA } \\
\operatorname{IgM}\end{array}$ & $n / s$ & $n / s$ & $n / s$ & 42 & $19.0 \% * *$ & $\begin{array}{l}\text { observed } \\
\text { cross-reaction } \\
\text { with WNV }\end{array}$ \\
\hline
\end{tabular}

* Indicates year of publication when year(s) of data collection not available in report.

${ }^{\dagger}$ All serologic assays were $\lg G$ unless otherwise stated.

**Indicates documented occurrence or suspicion of false-positives due to cross-reactions with other same family viruses or low serologic titers.

Abbreviations: AFI, acute febrile illness patients; Ag, antigen; CF, complement fixation; Conv, convenience; ELISA, enzyme-linked immunosorbent assay; $\mathrm{HI}$, hemagglutinin inhibition; ICT, immunochromatography test; IIFA, indirect immunofluorescence antibody test; MSCS, multi-stage cluster sampling; n/s, not specified; NS1, NS1 antigen test; PA, purified antigen; PCR, polymerase chain reaction; pop., population; PS, purposive sampling; RSS, random stratified sampling; SRS, simple random sampling; SSCS, single stage cluster sampling; VNT, viral neutralization test

Assay Abbreviation: CDC (Centers for Disease Control and Prevention, USA); Chemicon (Chemicon, Temecula, CA, USA); Diag. Auto. (Diagnostic Automation, CA, USA); DRG (DRG International Inc); Euroimmun (Lubeck, Germany); Focus (Focus Diagnostics, Cypress CA, USA); Genlab (Genlab Diagnostics, Singapore); GmbH (Human GmbH, Wiesbaden, Germany); MRL Diagnostics (Cypress CA, USA); NovaLisa (Dietzenbach, Germany); Omega (Omega Diagnostics, Scotland, UK); PanBio (Brisbane, Australia); Progen (Heidelberg, Germany); SD Bioline (Standard Diagnostics, Korea); Vircell (Vircell Microbiologists, Granada, Spain)

doi:10.1371/journal.pntd.0005194.t003

( $\mathrm{n}=3,9-28 \%)$, Saudi Arabia $(\mathrm{n}=4,0-33 \%)$, and Sudan $(\mathrm{n}=5,9-49 \%)$. ELISAs were the most commonly used diagnostic method for all study types and the majority studies from the MENA used in-house assays (Table 4). VNT results were reported in 3\% $(n=3)$ of all studies while observed or potential serologic cross-reactions with other flaviviruses were present in multiple studies [36-38] (Tables 3 and 4). Three human incidence measures for DENV were identified (Table 5): the first reported an ELISA IgM incidence of 35 cases per 10,000 people living in urban homes in Port Sudan City, Sudan where DENV-carrying mosquitoes were identified over an 11-month period [39]; the second reported an ELISA IgM incidence of 94 cases per 10,000 people in a general population in Port Sudan, Sudan over a 17-week period in 2010 [40]; the third reported an ELISA IgM, NS1 antigen, or PCR incidence of 185 cases per 100,000 febrile children in an urban slum in Karachi, Pakistan from 1999-2001 [41]. Three vector infection rate studies for Ae. aegypti and Ae. albopictus were identified from Pakistan and Yemen $[42,43]$ (Table 6).

\section{Risk of bias assessment results}

The quality assessment for each study is found in S1 Table and a summary of the precision and risk of bias assessment is found in Table 4 . In brief, most studies ( $\geq 65 \%$ ) contained high precision as defined by a sample size of $\geq 100$ participants. A minority (36\%) of general population seroprevalence studies utilized some form of random sampling, and response rates were either $<80 \%$ or not reported in $86 \%$ of general population studies. VNT or a biologic confirmatory assay (i.e. cell culture, PCR, and NS1 ELISA) was performed in 5\% and 36\% of general 


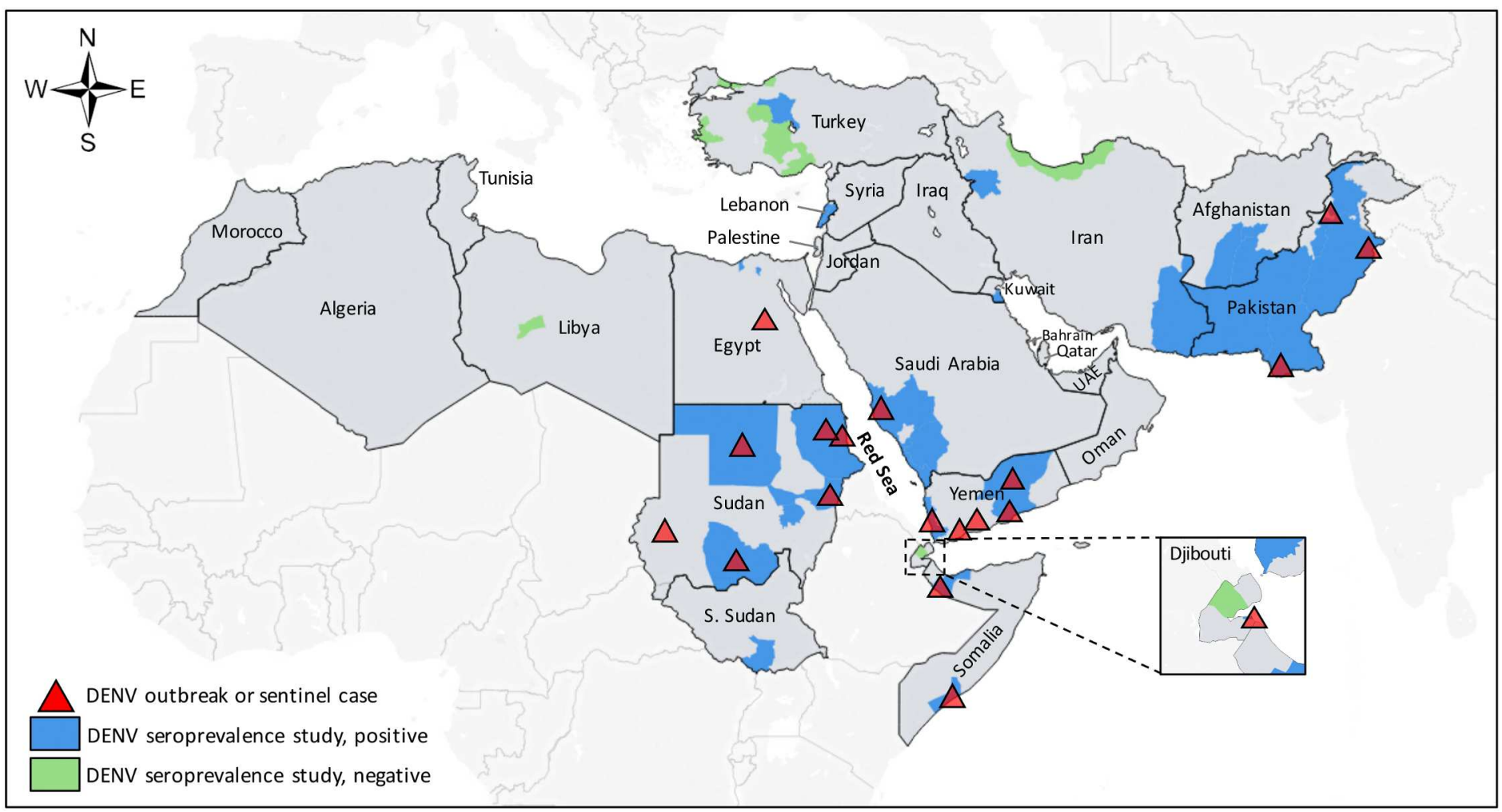

Fig 2. Geographic distribution of human prevalence studies and reported outbreaks of dengue in the Middle East and North Africa.

doi:10.1371/journal.pntd.0005194.g002

population seroprevalence and acute DENV infection studies, respectively, entailing low ROB for the assays used.

\section{Dengue outbreaks and Aedes occurrence}

Reported outbreaks of DENV in the region were gathered through citations collected from the search databases (S2 Table) and mapped along with the geographic distribution of prevalence studies in Fig 2. For DENV, 81 outbreaks were reported from 9 countries in the region from 1941-2015, including sentinel reports of autochthonous transmission in Egypt (2010) and Yemen (1983). Reports contained variable descriptions of outbreaks including 'estimated', 'suspected', 'reported', and/or laboratory 'confirmed' cases (S2 Table). The definition that qualified each event as an outbreak was unclear in most instances. Outbreaks of DENV serotypes 1-3 were reported from countries surrounding the Red Sea and DENV-4 was only reported from Pakistan [120, 121]. Although, in general, DENV serotypes were not reported consistently.

Published reports of Ae. aegypti and Ae. albopictus occurrence are recorded in S3 Table and mapped by country in Fig 3. Ae. aegypti occurrence was reported in 11 MENA countries and historically (i.e. prior to 1960) in Algeria, Libya, Morocco, Syria, and Tunisia. Ae. albopictus was reported in seven MENA countries, including Algeria, Palestine, and Syria, countries where Ae. aegypti is not currently reported. No published reports of Ae. aegypti or Ae. albopictus occurrence (or DENV outbreaks) were identified in seven MENA countries: Bahrain, Iran, Iraq, Jordan, Kuwait, Qatar, and United Arab Emirates. Since 2005, Ae. aegypti and/or Ae. albopictus occurrence has been documented in Afghanistan, Algeria, Lebanon, Oman, Palestine, Syria, and Turkey, though autochthonous transmission of DENV has not yet been reported from these countries. 
Table 4. Summary of human prevalence studies for dengue virus in the Middle East and North Africa $(n=103)$.

\begin{tabular}{|c|c|c|c|}
\hline Study characteristics & General population $(n=42) n(\%)$ & Acute febrile illness $(n=23) n(\%)$ & Suspected dengue $(n=38) n(\%)$ \\
\hline Total sample size & 24,377 & 4,065 & 33,955 \\
\hline Median DENV \% prevalence (range \%) & $25 \%(0-61.9)$ & $15.2 \%(0-87.5)$ & $47.4 \%(6.8-100)$ \\
\hline \multicolumn{4}{|l|}{ Year of study } \\
\hline before 1990 & $21(50 \%)$ & $7(30 \%)$ & 0 \\
\hline 1990 to 2015 & $21(50 \%)$ & $16(70 \%)$ & $38(100 \%)$ \\
\hline \multicolumn{4}{|l|}{ Study setting } \\
\hline community & $31(74 \%)^{\dagger}$ & $2(9 \%)$ & $2(5 \%)$ \\
\hline clinic or hospital & $11(26 \%)$ & $21(91 \%)$ & $36(95 \%)$ \\
\hline \multicolumn{4}{|l|}{ Assay } \\
\hline ELISA IgG & $19(45 \%)$ & $8(35 \%)$ & $10(26 \%)$ \\
\hline ELISA IgM & $11(26 \%)$ & $17(74 \%)$ & $31(82 \%)$ \\
\hline immunofluorescence antibody & $5(12 \%)$ & $2(9 \%)$ & $2(5 \%)$ \\
\hline hemagglutination inhibition & $15(36 \%)$ & $5(22 \%)$ & $2(5 \%)$ \\
\hline complement fixation & $1(2 \%)$ & $1(4 \%)$ & 0 \\
\hline viral neutralization & $2(5 \%)$ & $1(4 \%)$ & 0 \\
\hline PCR & 0 & $4(17 \%)$ & $14(37 \%)$ \\
\hline cell culture & 0 & $3(13 \%)$ & $1(3 \%)$ \\
\hline NS1 antigen & $2(5 \%)$ & 0 & $1(3 \%)$ \\
\hline \multicolumn{4}{|l|}{ Assay make } \\
\hline in-house & $21(50 \%)$ & $10(43 \%)$ & $11(29 \%)$ \\
\hline commercial & $20(48 \%)$ & $10(43 \%)$ & $15(39 \%)$ \\
\hline not specified & $1(2 \%)$ & $3(13 \%)$ & $12(32 \%)$ \\
\hline \multicolumn{4}{|l|}{ Target protein** } \\
\hline whole virus & $32(76 \%)$ & $12(52 \%)$ & $6(16 \%)$ \\
\hline envelope & $7(17 \%)$ & $4(17 \%)$ & $9(24 \%)$ \\
\hline not specified & $3(7 \%)$ & $7(30 \%)$ & $21(55 \%)$ \\
\hline \multicolumn{4}{|l|}{ Risk of bias summary } \\
\hline \multicolumn{4}{|l|}{ Assay } \\
\hline low risk of bias & $2(5 \%)$ & $8(35 \%)$ & $14(37 \%)$ \\
\hline high risk of bias & $40(95 \%)$ & $15(65 \%)$ & $24(63 \%)$ \\
\hline unclear risk of bias & 0 & 0 & $1(3 \%)$ \\
\hline \multicolumn{4}{|l|}{ Sampling methodology } \\
\hline low risk of bias & $15(36 \%)$ & $\mathrm{n} / \mathrm{a}$ & $\mathrm{n} / \mathrm{a}$ \\
\hline high risk of bias & $17(40 \%)$ & $\mathrm{n} / \mathrm{a}$ & $\mathrm{n} / \mathrm{a}$ \\
\hline unclear risk of bias & $10(24 \%)$ & $\mathrm{n} / \mathrm{a}$ & $\mathrm{n} / \mathrm{a}$ \\
\hline \multicolumn{4}{|l|}{ Response rate } \\
\hline low risk of bias & $6(14 \%)$ & $11(48 \%)$ & $22(58 \%)$ \\
\hline high risk of bias & $1(3 \%)$ & 0 & 0 \\
\hline unclear risk of bias & $35(83 \%)$ & $12(52 \%)$ & $16(42 \%)$ \\
\hline \multicolumn{4}{|l|}{ Precision } \\
\hline High & $28(67 \%)$ & $15(65 \%)$ & $28(74 \%)$ \\
\hline Low & $14(33 \%)$ & $8(35 \%)$ & $10(26 \%)$ \\
\hline
\end{tabular}

* $N=103$ because the study type (i.e. general prevalence, acute febrile illness, or suspected dengue) was not specified in two studies [51, 57].

${ }^{\dagger}$ Community study settings also include animal quarantine station $(n=1)$, blood donation center $(n=5)$, military $(n=3)$, and university $(n=1)$.

** Indicates the target protein for the initial screening assay for studies in which multiple diagnostic assays were utilized.

doi:10.1371/journal.pntd.0005194.t004 
Table 5. Summary of human incidence studies for dengue virus in the Middle East and North Africa $(n=3)$.

\begin{tabular}{|c|c|c|c|c|c|c|c|c|c|c|c|c|}
\hline $\begin{array}{l}\text { Country, } \\
\text { Ref. }\end{array}$ & $\begin{array}{l}\text { Year } \\
\text { (s) of } \\
\text { study }\end{array}$ & $\begin{array}{l}\text { Duration } \\
\text { of follow- } \\
\text { up }\end{array}$ & $\begin{array}{c}\text { City or } \\
\text { governorate }\end{array}$ & $\begin{array}{l}\text { Setting; } \\
\text { population(age } \\
\text { range, years) }\end{array}$ & $\begin{array}{l}\text { Study } \\
\text { design }\end{array}$ & Sampling & $\begin{array}{l}\text { Assay } \\
\text { type }\end{array}$ & $\begin{array}{l}\text { Assay } \\
\text { make }^{+}\end{array}$ & $\begin{array}{l}\text { Assay } \\
\text { Target }\end{array}$ & $\begin{array}{l}\text { Serotype } \\
\text { tested }\end{array}$ & $\begin{array}{c}\text { Sample } \\
\text { size }\end{array}$ & Incidence \\
\hline \multicolumn{13}{|c|}{ Pakistan $(n=1)$} \\
\hline $\begin{array}{l}\text { Siddiqui } \\
\text { [41] }\end{array}$ & $\begin{array}{l}1999- \\
2001\end{array}$ & $\begin{array}{l}1999- \\
2001\end{array}$ & Karachi & $\begin{array}{c}\text { Urban slum; } \\
\text { children }<16 \\
\text { years of age with } \\
\text { undifferentiated } \\
\text { febrile illness }\end{array}$ & CS & $\begin{array}{c}\text { Active } \\
\text { surveillance }\end{array}$ & $\begin{array}{l}\text { ELISA } \\
\text { IgM }\end{array}$ & $\begin{array}{l}\text { Diag. } \\
\text { Auto. }\end{array}$ & wV & $1-4$ & 1,248 & $\begin{array}{c}185 / \\
100,000\end{array}$ \\
\hline \multicolumn{13}{|l|}{ Sudan $(n=2)$} \\
\hline $\begin{array}{l}\text { Seidahmed } \\
\text { [39] }\end{array}$ & $\begin{array}{c}2008- \\
09\end{array}$ & $\begin{array}{c}12 \\
\text { months }\end{array}$ & $\begin{array}{l}\text { Port Sudan } \\
\quad \text { City }\end{array}$ & $\begin{array}{c}\text { Urban } \\
\text { community; } \\
\text { general pop. } \\
\text { living in houses } \\
\text { where DENV- } \\
\text { carrying } \\
\text { mosquitoes were } \\
\text { present }(<1-80)\end{array}$ & $\begin{array}{l}\text { Pros. } \\
\text { coh }\end{array}$ & RSS & $\begin{array}{l}\text { ELISA } \\
\text { IgM }\end{array}$ & PanBio & Env & $1-4$ & 791 & $35 / 10,000$ \\
\hline $\begin{array}{l}\text { Seidahmed } \\
\text { [40] }\end{array}$ & 2010 & 17 weeks & Port Sudan & $\begin{array}{c}\text { Urban } \\
\text { community; } \\
\text { general pop. }\end{array}$ & CS & Conv. & $\begin{array}{l}\text { ELISA } \\
\text { IgM, } \\
\text { NS1, } \\
\text { PCR }\end{array}$ & $\mathrm{n} / \mathrm{s}$ & $n / s$ & $n / s$ & $3,765^{\ddagger}$ & $94 / 10,000$ \\
\hline
\end{tabular}

\section{‡ Reported cases}

Abbreviations: CS, cross-sectional; ELISA, enzyme-linked immunosorbent assay; Env, envelope; PCR, polymerase chain reaction; Pros. coh, prospective cohort; RSS, random stratified sampling

Assay Abbreviation: Diag. Auto. (Diagnostic Automation, CA, USA); PanBio (Brisbane, Australia)

doi:10.1371/journal.pntd.0005194.t005

\section{Discussion}

Our study offers an assessment of published prevalence, incidence, and outbreak reports pertaining to the epidemiology of dengue in the MENA region. Based on the study results, the MENA contains two apparent subregions known to harbor DENV: 1) Pakistan, and 2) the Red Sea countries (Djibouti, Egypt, Saudi Arabia, Somalia, Sudan, and Yemen). No seroprevalence or outbreak data was identified across broad areas of the MENA, however, including some Aedes endemic areas. There was also a paucity of reports estimating human incidence and vector infection rates. These findings suggest priorities for future research. However, they also

Table 6. Summary of vector infection rate studies for dengue virus in the Middle East and North Africa $(n=3)$

\begin{tabular}{|c|c|c|c|c|c|c|c|c|}
\hline $\begin{array}{c}\text { Author, } \\
\text { Ref. }\end{array}$ & $\begin{array}{c}\text { Year(s) of data } \\
\text { collection }\end{array}$ & $\begin{array}{c}\text { City or } \\
\text { governorate }\end{array}$ & Setting & $\begin{array}{l}\text { Mosquito } \\
\text { species }\end{array}$ & $\begin{array}{l}\text { Assay } \\
\text { type }\end{array}$ & Sample size & $\begin{array}{l}\text { Infection } \\
\text { rate }\end{array}$ & Comments \\
\hline \multicolumn{9}{|l|}{ Pakistan } \\
\hline \multirow[t]{2}{*}{$\begin{array}{l}\text { Jahan } \\
\text { [42] }\end{array}$} & 2011 & Lahore & Urban areas & Ae. aegypti & $\begin{array}{l}\text { Ag-capture } \\
\text { ELISA }\end{array}$ & $\begin{array}{c}114 \text { pools } \\
(n=570 \\
\text { mosquitoes) }\end{array}$ & $27.2 \%$ & \\
\hline & & & & $\begin{array}{c}\text { Ae. } \\
\text { albopictus }\end{array}$ & $\begin{array}{l}\text { Ag-capture } \\
\text { ELISA }\end{array}$ & $\begin{array}{c}4 \text { pools }(n=20 \\
\text { mosquitoes) }\end{array}$ & $25 \%$ & \\
\hline \multicolumn{9}{|l|}{ Yemen } \\
\hline $\begin{array}{l}\text { Zayed } \\
\text { [43] }\end{array}$ & $2010-11$ & Al Hodayda & $\begin{array}{l}\text { houses of } \mathrm{CHIKV} \\
\text { cases at Eritrean } \\
\text { refugee camp }\end{array}$ & Ae. aegypti & RT-PCR & $\begin{array}{c}11 \text { pools }(n=30 \\
\text { mosquitoes) }\end{array}$ & $0 \%$ & $\begin{array}{c}17 \text { Culex spp. } \\
\text { mosquitoes were also } \\
\text { negative for DENV RNA. }\end{array}$ \\
\hline
\end{tabular}

Abbreviations: RT-PCR, reverse transcription-polymerase chain reaction

doi:10.1371/journal.pntd.0005194.t006 


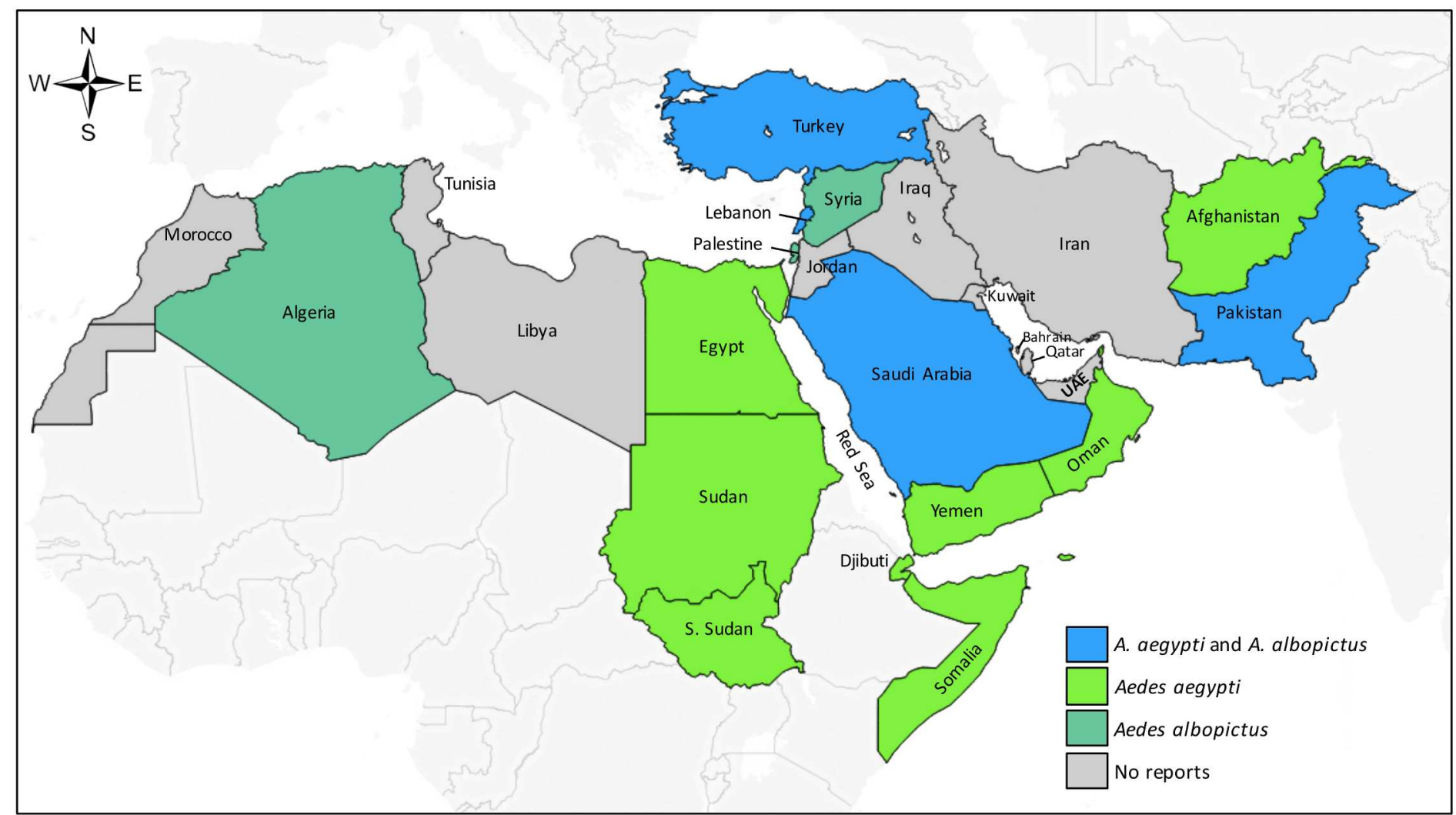

Fig 3. Country-level distribution of Aedes aegypti and Aedes albopictus occurrence in the Middle East and North Africa.

doi:10.1371/journal.pntd.0005194.g003

challenge efforts to synthesize and compare the inter- and intra-country epidemiology of DENV in the region.

\section{Dengue seroprevalence in the MENA}

In our review, Pakistan reported the highest number of prevalence studies and the broadest study coverage among MENA countries. Multiple studies reported $>20 \%$ prevalence in both general population and those with undifferentiated AFI [1, 106, 122-124]. DENV serotypes 1-4 are known to circulate in Pakistan, unlike other MENA countries [82]. Pakistan also reported the largest number of confirmed cases among all DENV outbreaks in the MENA, with 21,580 cases reported during the 2011 DENV-2 outbreak [79, 120] (S2 Table).

In the Red Sea region, multiple general population and AFI population IgG seroprevalence measures exceeding 20\% were published from in Djibouti, Saudi Arabia, Somalia, Sudan, and Yemen within the past decade (Table 3) along with multiple confirmed outbreaks of DENV serotypes 1-3 since the 1980s (S2 Table). DENV-4 has not yet been identified in this subregion to our knowledge. Although reported outbreaks and cases often localize along the Red Sea coastline in these countries [1], seroprevalence studies suggest a broader distribution of DENV infections that are likely underdetected (Fig 2). This is illustrated by the sentinel report of a DENV-infected traveler returning from Yemen in 1983 [125], despite the first outbreaks of DENV in Yemen and Saudi Arabia not being reported until 1994 [126-128]. Our search also identified no published prevalence studies or outbreaks in Egypt after 1969 until a dengue outbreak was reported in November 2015 [10]. However, DENV transmission was suggested years prior by a report of two travelers diagnosed with dengue after returning from southern 
Egypt in 2011 [129] and the identification of Ae. aegypti in southern Egypt that same year [130]. It is plausible that undetected DENV transmission had been occurring in Egypt prior to this outbreak. However, it is not clear whether this and other recent outbreaks represent increasing incidence, increasing detection, or both, amidst the heterogeneity in study coverage and reporting in the MENA.

\section{Clinical and methodological diversity among studies}

An important finding in our study was the clinical and methodological diversity among DENV prevalence studies. This diversity represents a challenge to synthesizing the epidemiologic literature for DENV in the MENA. Clinically, studies represented a diversity of human populations of different ages and demographics, in different years, and different locations and transmission contexts. Ninety-six percent of studies from Afghanistan, Pakistan, Saudi Arabia, Somalia, and Yemen were conducted during or prior to 1990 . However, $53 \%$ of studies in other MENA countries were conducted prior to 1990, when study methods and DENV epidemiology may have been different. Methodologically, most studies utilized convenience samples without reporting response rates, entailing high risk of bias and uncertainty in the representativeness of reported measures (Table 4). These findings, along with the high variability in regional study coverage, precluded meta-analyses of the available data.

\section{Flavivirus cross-reactivity}

Serologic cross-reactions remain a challenge to seroepidemiologic studies for DENV and other flaviviruses. Viral neutralization tests, considered the gold standard serologic assay for DENV, were performed in only $5 \%$ of general population seroprevalence studies in our review. Compared to ELISAs, seroprevalence measures were $22-86 \%$ lower by secondary/confirmatory testing with immunofluorescence or VNT in our review [14, 36, 37, 113]. This illustrates the potential uncertainty surrounding the reliability of ELISAs in DENV serologic studies, particularly in areas where the prevalence of antigenically similar viruses is broad or unknown. West Nile virus (WNV), for example, is thought to be distributed across the MENA on account of its ubiquitous Culex spp. vector and migratory bird flyways [131-133]. With up to $80 \%$ of WNV infections occurring subclinically, the potential for serologic cross-reactions with DENV antibody assays must be considered. Yellow fever vaccine-derived and natural antibodies may also cross-react with anti-DENV antibodies, especially relevant in YFV endemic regions such as Sudan $[38,107,111]$. As the emergence of zika virus in the Western Hemisphere or the re-emergence of YFV has shown, serologic assays with low specificity are inadequate to tackle the epidemiologic challenges of emerging arboviral diseases [134].

\section{Heterogeneity in dengue outbreak reports}

Our review identified DENV outbreaks in over a third of MENA countries, with most outbreaks reported from Pakistan, Sudan, and Saudi Arabia (S2 Table). Outbreaks varied widely across time and space in the MENA: reported cases varied from $<10$ to $>100,000$ over a span of months to years, reported from the village level to the level of the province and region. This presents a challenge to epidemiologic monitoring and policy planning for DENV, as use of different outbreak definitions results in differences in early detection and response [30]. There is currently no consensus on how to define DENV outbreaks, and adopting a common definition for the MENA is challenging given the region's heterogeneous infection pressures, multiple DENV serotypes, and variable surveillance and detection capacity. At present, assessing whether a reported transmission event in the MENA significantly deviates from baseline transmission, and thus constitutes an outbreak, is often unclear. 


\section{Risk factors and research priorities}

Our study did not identify confirmed DENV transmission in any of the MENA countries west of Egypt and east of Saudi Arabia until Pakistan (Fig 2). However, the paucity of published data in these sub-regions does not preclude the possibility of unrecognized transmission in some areas or the risk of emergence in others. Indeed, modeling studies suggest ecologic niches for Aedes along the coastal Mediterranean Basin of North Africa [1, 123, 135], and Ae. albopictus and/or Ae. aegypti has been recently reported in Algeria, Lebanon, Palestine, Syria, and Turkey [5, 136-140] (Fig 3 and S3 Table). In contrast, Ae. albopictus has been identified along the Mediterranean coast of Europe for decades along with local transmission of DENV and chikungunya since 2007 [141]. Near the Pakistan border, serologic evidence suggests possible DENV transmission in Iran $[14,51,53]$ and Afghanistan [44], though local transmission has not been confirmed to our knowledge [53]. The presence of Aedes or DENV transmission in these areas should not be ruled out [53].

Several ecologic and social factors in the MENA may promote the spread of Aedes-borne viruses like DENV. Urbanization [142] may increase the risk of outbreaks and use of open water storage containers that promote Ae. aegypti breeding [1, 39, 43, 55, 95, 111, 123, 135]. Heavy rainfall has been implicated in DENV outbreaks in Sudan, Djibouti, and Yemen [12, 47, 143, 144], which may become increasingly unpredictable through climate change [145]. Armed conflicts and economic turmoil in Iraq, Syria, and Yemen may render these areas vulnerable to vector-borne diseases while diminishing surveillance and response [146]. Inter-regional migration poses risk for imported DENV, as millions of migrants travel from DENV-endemic countries to the Arabian Peninsula [111, 126, 146-149] and to Mecca, Saudi Arabia to attend Umra and Hajj [126]. Intraregionally, heavy commerce in the Red Sea region likely drives DENV serotype mixing and spread $[116,148]$, as evidenced by multiple DENV outbreaks occurring at port cities in Djibouti [37, 45], Saudi Arabia [126], Sudan [39], and Yemen [116, 148]. Contiguous spread of DENV from Yemen to Oman [150], or from Pakistan to Iran or Afghanistan [14], may also pose risk.

A number of research priorities emerge concerning the epidemiology of DENV in the MENA. First, broader seroepidemiologic coverage in the region is needed. Such studies are efficient means of characterizing infection pressures in populations lacking surveillance and diagnostic capacity. Multiplexed diagnostics are increasingly available and are well-suited for concurrently exploring the distribution other undercharacterized arboviruses in the region (e.g. Alkhumra, Chikungunya, Crimean-Congo Hemorrhagic Fever, O'Nyong-nyong, Rift Valley Fever, Sandfly Fever virus complex, Usutu, and West Nile viruses). Second, serologic studies should include methods to minimize cross-reactions, particularly for flaviviruses [151]. Third, seroepidemiologic studies should incorporate uniformity in study design and enrollment criteria to minimize confounding, such as standard case definitions for studies of 'suspected' dengue [126]. Ideally this could include population-based sampling that provides baseline data to benchmark the regional impact of these pathogens over the coming years. Fourth, studies should incorporate vector surveillance and infection rates. Such studies are important for understanding transmission dynamics that inform vector control strategies and predict future transmission and disease risk [123, 135, 141]. Guidelines and tools for calculating vector infection rates are available [141,152]. Finally, attaining a meaningful definition of DENV outbreaks in the MENA countries will require a thorough assessment of baseline surveillance, control, and treatment capacities in endemic regions [30].

\section{Study limitations}

Our study was limited by its reliance on select databases of peer-reviewed literature screened by one investigator with the exclusion of grey literature which may have provided additional 
data. Reviewing other Aedes-transmitted pathogens or studies reporting Aedes distribution in the MENA may also have provided further insights regarding the potential geographic distribution of DENV. Due to the limitations in the content and distribution of studies, we did not perform a meta-analysis nor did we explore bias in overall outcome measures through a funnel plot or Egger test. Non-publication of studies with small or zero effect size or studies targeted to known dengue-endemic areas may have biased the distribution and quantity of DENV studies. The prevalence measures themselves may have been biased through serologic-cross reactions, targeting of older study populations (with higher seroprevalence), and lack of convalescent titers for acute DENV infection studies (possibly underestimating seroprevalence).

\section{Conclusions}

DENV seroprevalence in the MENA is high among some populations in the Red Sea region and Pakistan, while recent outbreaks in these subregions suggest increasing DENV incidence driven by ecologic and social factors. Published prevalence and incidence, vector occurrence, and vector infection rates are lacking in broad areas of the MENA and available studies contain methodological limitations. These findings illustrate the need to strengthen programs for surveillance, reporting, and control of DENV and Aedes in the MENA, both to define DENV and Aedes epidemiology and to mitigate the risk of emerging Aedes-transmitted pathogens in the future.

\section{Supporting Information}

S1 Fig. Preferred Reporting Items for Systematic Reviews and Meta-analyses (PRISMA) checklist.

S2 Fig. Data sources and search criteria used for the systematic review of dengue virus prevalence and incidence in the Middle East and North Africa. (PDF)

S1 Table. Precision and risk of bias assessment for dengue prevalence measures in the Middle East and North Africa.

S2 Table. Summary of reported outbreaks and sentinel cases for dengue virus in the Middle East and North Africa.

(PDF)

S3 Table. Reported Aedes aegypti and Aedes albopictus occurrence in the Middle East and North Africa.

(PDF)

\section{Acknowledgments}

We would like to thank Mary Charlson and Carol Mancuso (Weill Cornell Graduate School of Medical Sciences, New York, USA) for their contributions to the study planning and organization, and Ghina Mumtaz, Hiam Chamaitelly, and Karima Chaabna (Weill Cornell Medical College in Qatar) for their assistance with the study methodology.

\section{Author Contributions}

Conceptualization: JMH NBC CBEMR MPGK LJAR. 
Formal analysis: JMH LJAR.

Investigation: JMH NBC.

Methodology: MJG MPGK LJAR.

Software: LJAR.

Supervision: MJG CBEMR MPGK LJAR.

Writing - original draft: JMH.

\section{References}

1. Bhatt S, Gething PW, Brady OJ, Messina JP, Farlow AW, Moyes CL, et al. The global distribution and burden of dengue. Nature. 2013; 496(7446):504-7. doi: 10.1038/nature12060 PMID: 23563266

2. Murray NE, Quam MB, Wilder-Smith A. Epidemiology of dengue: past, present and future prospects. Clin Epidemiol. 2013; 5:299-309. doi: 10.2147/CLEP.S34440 PMID: 23990732

3. Gubler DJ. The global resurgence of arboviral diseases. Trans R Soc Trop Med Hyg. 1996; 90 (5):449-51. PMID: 8944250

4. H.R. R. The role of vectors in emerging and re-emerging diseases in the Eastern Mediterranean Region. East Mediterr Health J. 1996; 2(1):61-7.

5. Garabedian GA, Matossian RM, Musalli MN. Serologic evidence of arbovirus infection in Lebanon. Le Journal medical libanais. 1971; The Lebanese medical journal. 24(4):339-50. PMID: 5149804

6. World Health Organization. Growing threat of viral haemorrhagic fevers in the Eastern Mediterranean Region: a call for action Regional Office for the Eastern Mediterranean. Cairo, Egypt. Available from: http://applications.emro.who.int/docs/em_rc54_r4_en.pdf?ua=1. Accessed 24 July 2014.

7. Hotez PJ, Savioli L, Fenwick A. Neglected tropical diseases of the Middle East and North Africa: review of their prevalence, distribution, and opportunities for control. PLoS Negl Trop Dis. 2012; 6(2): e1475. doi: 10.1371/journal.pntd.0001475 PMID: 22389729

8. Rai MA. Epidemic: Control of dengue fever in Pakistan. Nature. 2011; 479(7371):41.

9. Arya SC, Agarwal N. Apropos: An update on the incidence of dengue gaining strength in Saudi Arabia and current control approaches for its vector mosquito. Parasites and Vectors. 2014; 7(1).

10. World Health Organization. Dengue Fever-Egypt 2015. Available from: http://www. who.int/csr/don/ 12-november-2015-dengue/en/. Accessed 12 Dec 2015.

11. World Health Organization. Neglected tropical diseases: an emerging public health problem in the Eastern Mediterranean Region. 54th Regional Committe meeting, Eastern Mediterranean Region. Cairo, Egypt. 2006. Available from http://applications.emro.who.int/docs/EM_RC54_10e_en.pdf. Accessed 12 Dec 2015.

12. Malik MR, Mnzava A, Mohareb E, Zayed A, Al Kohlani A, Thabet AA, et al. Chikungunya outbreak in Al-Hudaydah, Yemen, 2011: epidemiological characterization and key lessons learned for early detection and control. J Epidemiol Glob Health. 2014; 4(3):203-11. doi: 10.1016/j.jegh.2014.01.004 PMID: 25107656

13. Chan EH, Brewer TF, Madoff LC, Pollack MP, Sonricker AL, Keller M, et al. Global capacity for emerging infectious disease detection. Proceedings of the National Academy of Sciences of the United States of America. 2010; 107(50):21701-6. doi: 10.1073/pnas.1006219107 PMID: 21115835

14. Aghaie A, Aaskov J, Chinikar S, Niedrig M, Banazadeh S, Mohammadpour HK. Frequency of dengue virus infection in blood donors in Sistan and Baluchestan province in Iran. Transfusion and Apheresis Science. 2014; 50(1):59-62. doi: 10.1016/j.transci.2013.07.034 PMID: 24332363

15. Elduma $\mathrm{AH}$, Osman WM. Dengue and hepatitis $\mathrm{E}$ virus infection in pregnant women in Eastern Sudan, a challenge for diagnosis in an endemic area. Pan Afr Med J. 2014; 19:391. doi: 10.11604/pamj.2014. 19.391.5439 PMID: 25995787

16. Burt FJ, Rolph MS, Rulli NE, Mahalingam S, Heise MT. Chikungunya: a re-emerging virus. Lancet. 2012; 379(9816):662-71. doi: 10.1016/S0140-6736(11)60281-X PMID: 22100854

17. Ali F, Saleem T, Khalid U, Mehmood SF, Jamil B. Crimean-congo hemorrhagic fever in a dengueendemic region: Lessons for the future. Journal of Infection in Developing Countries. 2010; 4(7):45963. PMID: 20818095 
18. Watts DM, El-Tigani A, Botros BAM, Salib AW, Olson JG, McCarthy M, et al. Arthropod-borne viral infections associated with a fever outbreak in the Northern Province of Sudan. Journal of Tropical Medicine and Hygiene. 1994; 97(4):228-30. PMID: 8064945

19. Bargaoui R, Lecollinet S, Lancelot R. Mapping the Serological Prevalence Rate of West Nile fever in Equids, Tunisia. Transbound Emerg Dis. 2013.

20. Ben Hassine T, De Massis F, Calistri P, Savini G, BelHaj Mohamed B, Ranen A, et al. First Detection of Co-circulation of West Nile and Usutu Viruses in Equids in the South-west of Tunisia. Transbound Emerg Dis. 2014; 61(5):385-9. doi: 10.1111/tbed.12259 PMID: 25065813

21. Higgins JP, Green S. Cochrane handbook for systematic reviews of interventions: Wiley Online Library; 2008.

22. Moher D, Liberati A, Tetzlaff J, Altman DG, Group P. Preferred reporting items for systematic reviews and meta-analyses: the PRISMA statement. PLoS medicine. 2009; 6(7):e1000097. doi: 10.1371/ journal.pmed.1000097 PMID: 19621072

23. McFarland W, Abu-Raddad LJ, Mahfoud Z, DeJong J, Riedner G, Forsyth A, et al. HIV/AIDS in the Middle East and North Africa: new study methods, results, and implications for prevention and care. AIDS. 2010; 24 Suppl 2:S1-4.

24. Google Translate Mountain View, California, USA. Available from: http://www.translate.google.com/. Accessed 30 Sept 2015.

25. The Cochrane collaboration. Cochrane handbook for systematic reviews of interventions. Hoboken (New Jersey): Wiley-Blackweill; 2008.

26. Chemaitelly H, Chaabna K, Abu-Raddad LJ. The Epidemiology of Hepatitis C Virus in the Fertile Crescent: Systematic Review and Meta-Analysis. PloS one. 2015; 10(8):e0135281. doi: 10.1371/journal. pone.0135281 PMID: 26296200

27. Mumtaz GR, Weiss HA, Thomas SL, Riome S, Setayesh H, Riedner G, et al. HIV among people who inject drugs in the Middle East and North Africa: systematic review and data synthesis. PLoS medicine. 2014; 11(6):e1001663. doi: 10.1371/journal.pmed.1001663 PMID: 24937136

28. Chaabna K, Mohamoud YA, Chemaitelly H, Mumtaz GR, Abu-Raddad LJ. Protocol for a systematic review and meta-analysis of hepatitis $\mathrm{C}$ virus (HCV) prevalence and incidence in the Horn of Africa sub-region of the Middle East and North Africa. Syst Rev. 2014; 3:146. PubMed Central PMCID: PMCPMC4274704. doi: 10.1186/2046-4053-3-146 PMID: 25516265

29. Galea S, Tracy M. Participation rates in epidemiologic studies. Ann Epidemiol. 2007; 17(9):643-53. doi: 10.1016/j.annepidem.2007.03.013 PMID: 17553702

30. Brady OJ, Smith DL, Scott TW, Hay SI. Dengue disease outbreak definitions are implicitly variable. Epidemics. 2015; 11:92-102. doi: 10.1016/j.epidem.2015.03.002 PMID: 25979287

31. Darwish MA, Hoogstraal H, Roberts TJ, Ahmed IP, Omar F. A sero-epidemiological survey for certain arboviruses (Togaviridae) in Pakistan. Transactions of the Royal Society of Tropical Medicine and Hygiene. 1983; 77(4):442-5. PMID: 6314612

32. Chastel C, Rogues G, Beaucournu-Saguez F. A mixed sero-epidemiologic survey on arbovirus-arenavirus in small mammalians in Tunisia. Bulletin de la Societe de Pathologie Exotique et de ses Filiales. 1977; 70(5):471-9. PMID: 615674

33. Chastel $\mathrm{C}$, Bach Hamba $\mathrm{D}$, Launay $\mathrm{H}$. New serosurvey on arbovirus infections in small wild mammals of Tunisia. Bulletin de la Societe de Pathologie Exotique et de ses Filiales. 1983; 76(1):21-33. PMID: 6839405

34. Ari A. The prevalence and ecology of arboviruses in Turkey. Turk hijiyen ve tecrubi biyoloji dergisi. 1972; 32(2):134-43. PMID: 4668350

35. Darwish MA, Ibrahim AH. A serological survey on group $A$ and $B$ arbovirus antibodies in Libya. Journal of the Egyptian Public Health Association. 1974; 49(1):20-6. PMID: 4850294

36. Omer AHS, McLaren ML, Johnson BK. A seroepidemiological survey in the Gezira, Sudan, with special reference to arboviruses. Journal of Tropical Medicine and Hygiene. 1981; 84(2):63-6. PMID: 7218404

37. Rodier GR, Gubler DJ, Cope SE, Cropp CB, Soliman AK, Polycarpe D, et al. Epidemic dengue 2 in the city of Djibouti 1991-1992. Transactions of the Royal Society of Tropical Medicine and Hygiene. 1996; 90(3):237-40. PMID: 8758061

38. Farnon EC, Gould LH, Griffith KS, Osman MS, El Kholy A, Brair ME, et al. Household-Based Sero-Epidemiologic Survey after a Yellow Fever Epidemic, Sudan, 2005. American Journal of Tropical Medicine and Hygiene. 2010; 82(6):1146-52. doi: 10.4269/ajtmh.2010.09-0105 PMID: 20519615

39. Seidahmed OME, Hassan SA, Soghaier MA, Siam HAM, Ahmed FTA, Elkarsany MM, et al. Spatial and Temporal Patterns of Dengue Transmission along a Red Sea Coastline: A Longitudinal Entomological and Serological Survey in Port Sudan City. PLoS Neglected Tropical Diseases. 2012; 6(9). 
40. Seidahmed OM, Siam HA, Soghaier MA, Abubakr M, Osman HA, Abd Elrhman LS, et al. Dengue vector control and surveillance during a major outbreak in a coastal Red Sea area in Sudan. East Mediterr Health J. 2012; 18(12):1217-24. PMID: 23301396

41. Siddiqui FJ, Haider SR, Bhutta ZA. Endemic Dengue Fever: A seldom recognized hazard for Pakistani children. Journal of Infection in Developing Countries. 2009; 3(4):306-12. PMID: 19759495

42. Jahan N. Detection of dengue viruses in aedes mosquitoes from different localities of Lahore, Pakistan. American Journal of Tropical Medicine and Hygiene. 2013;1: ):35.

43. Zayed A, Awash AA, Esmail MA, Al-Mohamadi HA, Al-Salwai M, Al-Jasari A, et al. Detection of Chikungunya virus in Aedes aegypti during 2011 outbreak in Al Hodayda, Yemen. Acta Tropica. 2012; 123(1):62-6. doi: 10.1016/j.actatropica.2012.03.004 PMID: 22469818

44. Elyan DS, Moustafa L, Noormal B, Jacobs JS, Aziz MA, Hassan KS, et al. Serological evidence of Flaviviruses infection among acute febrile illness patients in Afghanistan. J Infect Dev Ctries. 2014; 8

(9):1176-80. doi: 10.3855/jidc.4183 PMID: 25212082

45. Salah S, Fox E, Abbatte EA, Constantine NT, Asselin P, Soliman AK. A negative human serosurvey of haemorrhagic fever viruses in Djibouti. Annales de l'Institut Pasteur Virology. 1988; 139(4):439-42. PMID: 2905609

46. Faulde MK, Spiesberger M, Abbas B. Sentinel site-enhanced near-real time surveillance documenting West Nile virus circulation in two Culex mosquito species indicating different transmission characteristics, Djibouti City, Djibouti. Journal of the Egyptian Society of Parasitology. 2012; 42(2):461-74. PMID: 23214223

47. Andayi F, Charrel RN, Kieffer A, Richet H, Pastorino B, Leparc-Goffart I, et al. A sero-epidemiological study of arboviral fevers in Djibouti, horn of Africa. PLoS Negl Trop Dis. 2014; 8(12):e3299. doi: 10. 1371/journal.pntd.0003299 PMID: 25502692

48. Mohammed YS, Sekeyova M, Gresikova M, el-Dawala K. Studies on arboviruses in Egypt. I. Hemagglutination-inhibition antibodies against arboviruses in human population of Alexandria and Abyss areas. The Indian journal of medical research. 1968; 56(4):381-5. PMID: 5687693

49. Mohammed YS, Gresikova M, Adamyova K, Ragib AHe-DK. Studies on arboviruses in Egypt. II. Contribution of arboviruses to the aetiology of undiagnosed fever among children. The Journal of hygiene. 1970; 68(3):491-5. PMID: 5272347

50. Darwish MA, Ibrahim AH. Prevalence of antibodies to arboviruses in Egypt. Results of a serologic survey among 1,113 university students. American Journal of Tropical Medicine and Hygiene. 1975; 24(6 I):981-5.

51. Saidi S. Survey of antibodies to arboviruses in human population of Iran. Pahlavi Medical Journal. 1971; 2(3):485-90.

52. Saidi S. Viral antibodies in preschool children from the Caspian area, Iran. Iranian Journal of Public Health. 1974; 3(2):83-91.

53. Chinikar S, Ghiasi SM, Shah-Hosseini N, Mostafavi E, Moradi M, Khakifirouz S, et al. Preliminary study of dengue virus infection in Iran. Travel Medicine and Infectious Disease. 2013; 11(3):166-9. doi: 10.1016/j.tmaid.2012.10.001 PMID: 23194952

54. Ibrahim SH, Darwish MA, Wahdan MH, El Ghoroury AAA. Survey for antibodies against group B arboviruses in man in Kuwait. Journal of the Egyptian Public Health Association. 1974; 49(2):77-95. PMID: 4427084

55. Al-Nakib W, Lloyd G, El-Mekki A, Platt G, Beeson A, Southee T. Preliminary report on arbovirus-antibody prevalence among patients in Kuwait: evidence of Congo/Crimean virus infection. Transactions of the Royal Society of Tropical Medicine and Hygiene. 1984; 78(4):474-6. PMID: 6435292

56. Pacsa A, Mustafa AS, Chaturvedi UC. Study of dengue virus infection in Kuwait. Dengue Bulletin. 2002; 26(pp 113-117).

57. Hatem J. The role of the laboratory in the surveillance of viral diseases in Lebanon. Journal Medical Libanais. 1972; 25(3):151-65.

58. Akram DS, Igarashi A, Takasu T. Dengue virus infection among children with undifferentiated fever in Karachi. Indian journal of pediatrics. 1998; 65(5):735-40. PMID: 10773930

59. Tariq W KS, Hussain A, Bhani E. Outbreak of dengue fever in Mangla and Mirpur area. Pak J Pathol. 2006; 17(3):122.

60. Jamil B, Hasan R, Zafar A, Bewley K, Chamberlain J, Mioulet V, et al. Dengue virus serotype 3, Karachi, Pakistan. Emerg Infect Dis. 2007; 13(1):182-3.

61. Khan E, Mehraj V, Nasir A, Khan NA, Billoo B, Moatter T, et al. Evaluation of two ELISA Assay Kits against RT-PCR for diagnosis of Dengue Virus Infection in a Hospital Setting in Karachi, Pakistan. Journal of the Pakistan Medical Association. 2009; 59(6):390-4. PMID: 19534376 
62. Khan E, Hasan R, Mehraj V, Nasir A, Siddiqui J, Hewson R. Co-circulations of two genotypes of dengue virus in 2006 out-break of dengue hemorrhagic fever in Karachi, Pakistan. Journal of Clinical Virology. 2008; 43(2):176-9. doi: 10.1016/j.jcv.2008.06.003 PMID: 18639489

63. Koo C, Nasir A, Hapuarachchi HC, Lee KS, Hasan Z, Ng LC, et al. Evolution and heterogeneity of multiple serotypes of Dengue virus in Pakistan, 2006-2011. Virology Journal. 2013.

64. Khan AH, Hayat AS, Masood N, Solangi NM, Shaikh TZ. Frequency and clinical presentation of dengue fever at tertiary care hospital of Hyderabad/Jamshoro. Journal of the Liaquat University of Medical and Health Sciences. 2010; 9(2):88-94.

65. Khan E, Kisat M, Khan N, Nasir A, Ayub S, Hasan R. Demographic and clinical features of dengue fever in Pakistan from 2003-2007: A retrospective cross- sectional study. PLoS ONE. 2010; 5(9):1-7.

66. Abbasi A, Butt N, Sheikh QH, Bhutto AR, Munir SM, Ahmed SM. Clinical features, diagnostic techniques and management of dual dengue and Malaria infection. Journal of the College of Physicians and Surgeons Pakistan. 2009; 19(1):25-9. PMID: 19149976

67. Tahir Z HS, Chaudhry A. Spatial and seasonal varation of dengue fever in Lahore 2008. Biomedica. 2010; 26(Jul-Dec.: ):166.

68. Murad H, Asahar RJ, Zaheen M, Shawali R. Outbreak investigation of Dengue fever in Sundia, Chakaiser, Shangla, Pakistan-2008. Journal of Ayub Medical College, Abbottabad: JAMC. 2014; 26 (4):571-6. PMID: 25672190

69. Mahmood K AH, Tahir M. Incidence of dengue haemorrhagic fever in local population of Lahore, Pakistan. Biomedica. 2009; 25(Jul.-Dec.):93-6.

70. Kidwai AA, Jamal Q, Saher, Mehrunnisa, Faroogi FU, Saleem U. Serodiagnosis of dengue infection using rapid immunochromatography test in patients with probable dengue infection. J Pak Med Assoc. 2010; 60(11):936-9. PMID: 21375198

71. Zafar H, Hayyat A, Akhtar N, Rizwan SF. Prevalence of undifferentiated fever in adults of Rawalpindi having primary dengue fever. JPMA The Journal of the Pakistan Medical Association. 2013; 63 (6):770-1. PMID: 23901683

72. Zafar H, Hayyat A, Akhtar N. Incidence of primary dengue viral infection in healthy adults of Rawalpindi, Pakistan. Journal of the Pakistan Medical Association. 2011; 61(10):1030-1. PMID: 22356047

73. Qureshi KA LA, Samoo AH. Screening for dengue virus infection at GMMMC hospital, Sukkur. Medical Forum Monthly. 2013; 24(4):6-8.

74. Khan H KQ, Khan BA, Arif M, Raza AAH. Retrospective analysis of 68 cases of dengue fever. Pak J Med Res. 2012; 51(1):18.

75. Hasan SR, Riaz M, Jafri FA. Characteristics and outcome of dengue infection; clinical perspective from a secondary care hospital of Karachi. Pakistan Journal of Medical Sciences. 2013; 29(1):115-8. doi: 10.12669/pjms.291.2742 PMID: 24353520

76. Umar S, Ashraf O, Umar M. Characteristics of febrile thrombocytopenia during dengue epidemic 2010 in Rawalpindi, Pakistan. International Journal of Infectious Diseases. 2011; 15:S114-S115.

77. Jameel T MK, Ghulam Choudhry N, Afzal NP, Paul RF. Changing hematologic parameters in dengue viral infections. J Ayub med Coll-Abbotabad-Pak. 2012; 24(1):3.

78. Naeem M SA, Batool S, Rubab S, Saba T, Riaz T, Mahmood A. Dengue fever; a clinical experience Professional Med J. 2014; 23(2):243-46.

79. Ahmed S, Mohammad WW, Hamid F, Akhter A, Afzal RK, Mahmood A. The 2011 dengue haemorrhagic fever outbreak in lahore-an account of clinical parameters and pattern of haemorrhagic complications. Journal of the College of Physicians and Surgeons Pakistan. 2013; 23(7):463-7. PMID: 23823947

80. ljaz T, ljaz S, Aslam S, Ahmad BM, Raja SA. A laboratory based study of dengue epidemic in the city of Lahore during year 2011. International Journal of Infectious Diseases. 2014; 21:136.

81. Rashid A KH, Nadeem UR. Dengue Hemorrhagic Fever / dengue shock syndrome. Professional Med J. 2012; 19(5):661.

82. Khan MA, Ellis EM, Tissera HA, Alvi MY, Rahman FF, Masud F, et al. Emergence and Diversification of Dengue 2 Cosmopolitan Genotype in Pakistan, 2011. PLoS ONE. 2013; 8(3).

83. Hasan Z, Atkinson B, Jamil B, Samreen A, Altaf L, Hewson R. Short report: Diagnostic testing for hemorrhagic fevers in Pakistan: 2007-2013. American Journal of Tropical Medicine and Hygiene. 1243; 91 (6):1243-6. doi: 10.4269/ajtmh.14-0383 PMID: 25311694

84. Ali A, Rehman HU, Nisar M, Rafique S, Ali S, Hussain A, et al. Seroepidemiology of dengue fever in Khyber Pakhtunkhawa, Pakistan. International Journal of Infectious Diseases. 2013; 17(7):e518-e23. doi: 10.1016/j.ijid.2013.01.007 PMID: 23523057 
85. Hisam A, Mahmood ur R, Khan MB, Kadir E, Azam N. Frequency of co-existence of dengue and malaria in patients presenting with acute febrile illness. JPMA The Journal of the Pakistan Medical Association. 2014; 64(3):247-51. PMID: 24864593

86. Assir MZK, Masood MA, Ahmad HI. Concurrent dengue and malaria infection in Lahore, Pakistan during the 2012 dengue outbreak. International Journal of Infectious Diseases. 2014; 18(1):41-6.

87. Fakeeh M, Zaki AM. Virologic and serologic surveillance for dengue fever in Jeddah, Saudi Arabia, 1994-1999. American Journal of Tropical Medicine and Hygiene. 2001; 65(6):764-7. PMID: 11791972

88. Fakeeh M, Zaki AM. Dengue in Jeddah, Saudi Arabia, 1994-2002. Dengue Bulletin. 2003; 27(pp 1318).

89. Khan NA, Azhar El, El-Fiky S, Madani HH, Abuljadial MA, Ashshi AM, et al. Clinical profile and outcome of hospitalized patients during first outbreak of dengue in Makkah, Saudi Arabia. Acta Tropica. 2008; 105(1):39-44. doi: 10.1016/j.actatropica.2007.09.005 PMID: 17983609

90. Ayyub M, Khazindar AM, Lubbad EH, Barlas S, Alfi AY, Al-Ukayli S. Characteristics of dengue fever in a large public hospital, Jeddah, Saudi Arabia. Journal of Ayub Medical College, Abbottabad: JAMC. 2006; 18(2):9-13. PMID: 16977805

91. Shahin $W$, Nassar A, Kalkattawi M, Bokhari H. Dengue fever in a tertiary hospital in Makkah, Saudi Arabia. Dengue Bulletin. 2009; 33(1):34-44.

92. Said SM EK, Alyan Z. Benign acute myositis in association with acute dengue viruses' infections. Egypt J Neurol Psychiatry Neurosurg. 2008; 45(1):193.

93. Memish ZA, Albarrak A, Almazroa MA, Al-Omar I, Alhakeem R, Assiri A, et al. Seroprevalence of Alkhurma and other hemorrhagic fever viruses, Saudi Arabia. Emerging Infectious Diseases. 2011; 17 (12):2316-8. doi: 10.3201/eid1712.110658 PMID: 22172587

94. Gamil MA, Eisa ZM, Eifan SA, Al-Sum BA. Prevalence of dengue fever in Jizan area, Saudi Arabia. Journal of Pure and Applied Microbiology. 2014; 8(1):225-31.

95. Al-Azraqi TA, El Mekki AA, Mahfouzc AA. Seroprevalence of dengue virus infection in Aseer and Jizan regions, Southwestern Saudi Arabia. Transactions of the Royal Society of Tropical Medicine and Hygiene. 2013; 107(6):368-71. doi: 10.1093/trstmh/trt022 PMID: 23474472

96. Ashshi AM. Serodetection of Dengue virus and its antibodies among blood donors in the western region of Saudi Arabia: a preliminary study. Blood Transfus. 2015; 13(1):135-8. doi: 10.2450/2014 0134-14 PMID: 25369603

97. Botros BAM, Watts DM, Soliman AK, Salib AW, Moussa MI, Mursal H, et al. Serological evidence of dengue fever among refugees, Hargeysa, Somalia. Journal of Medical Virology. 1989; 29(2):79-81. PMID: 2600591

98. Kanesa-thasan N, lacono-Connors L, Magill A, Smoak B, Vaughn D, Dubois D, et al. Dengue serotypes 2 and 3 in US forces in Somalia. Lancet. 1994; 343(8898):678.

99. Sharp TW, Wallace MR, Hayes CG, Sanchez JL, DeFraites RF, Arthur RR, et al. Dengue fever in U.S. troops during Operation Restore Hope, Somalia, 1992-1993. Am J Trop Med Hyg. 1995; 53(1):89-94. PMID: 7625541

100. Nur YA, Groen J, Yusuf MA, Osterhaus ADME. IgM antibodies in hospitalized children with febrile illness during an inter-epidemic period of measles, in Somalia. Journal of Clinical Virology. 1999; 12 (1):21-5. PMID: 10073410

101. Kyobe Bosa H, Montgomery JM, Kimuli I, Lutwama JJ. Dengue fever outbreak in Mogadishu, Somalia 2011: Co-circulation of three dengue virus serotypes. International Journal of Infectious Diseases. 2014; $21: 3$.

102. Hyams KC, Oldfield EC, McNair Scott R. Evaluation of febrile patients in Port Sudan, Sudan: Isolation of dengue virus. American Journal of Tropical Medicine and Hygiene. 1986; 35(4):860-5. PMID: 3728800

103. Woodruff PWR, Morrill JC, Burans JP, Hyams KC, Woody JN. A study of viral and rickettsial exposure and causes of fever in Juba, southern Sudan. Transactions of the Royal Society of Tropical Medicine and Hygiene. 1988; 82(5):761-6. PMID: 2855284

104. McCarthy MC, Haberberger RL, Salib AW, Soliman BA, El-Tigani A, Khalid IO, et al. Evaluation of arthropod-borne viruses and other infectious disease pathogens as the causes of febrile illnesses in the Khartoum province of Sudan. Journal of Medical Virology. 1996; 48(2):141-6. doi: 10.1002/(SICI) 1096-9071(199602)48:2<141::AID-JMV4>3.0.CO;2-9 PMID: 8835346

105. Ibrahim SA, Mustafa OM, Mukhtar MM, Saleh EA, El Mubarak HS, Abdallah A, et al. Measles in suburban Khartoum: An epidemiological and clinical study. Tropical Medicine and International Health. 2002; 7(5):442-9. PMID: 12000654 
106. Malik A, Earhart K, Mohareb E, Saad M, Saeed M, Ageep A, et al. Dengue hemorrhagic fever outbreak in children in Port Sudan. Journal of Infection and Public Health. 2011; 4(1):1-6. doi: 10.1016/j.jiph. 2010.08.001 PMID: 21338953

107. Gould LH, Osman MS, Farnon EC, Griffith KS, Godsey MS, Karch S, et al. An outbreak of yellow fever with concurrent chikungunya virus transmission in South Kordofan, Sudan, 2005. Transactions of the Royal Society of Tropical Medicine and Hygiene. 2008; 102(12):1247-54. doi: 10.1016/j.trstmh.2008. 04.014 PMID: 18502458

108. Adam I, Jumaa AM, Elbashir HM, Karsany MS. Maternal and perinatal outcomes of dengue in PortSudan, Eastern Sudan. Virology Journal. 2010; 7(153).

109. Himatt S, Osman KE, Okoued SI, Seidahmed OE, Beatty ME, Soghaier MA, et al. Sero-prevalence of dengue infections in the Kassala state in the eastern part of the Sudan in 2011. J Infect Public Health. 2015.

110. Abdalla TM, Karsany MS, Ali AA. Correlation of measles and dengue infection in Kassala, Eastern Sudan. J Med Virol. 2014.

111. Soghaier MA, Mahmood SF, Pasha O, Azam SI, Karsani MM, Elmangory MM, et al. Factors associated with dengue fever IgG sero-prevalence in South Kordofan State, Sudan, in 2012: Reporting prevalence ratios. Journal of Infection and Public Health. 2014; 7(1):54-61. doi: 10.1016/j.jiph.2013.07. 008 PMID: 24210245

112. Radda A. Studies on the activity and ecology of arboviruses in Turkey. ZblBaktReihe A. 1973; 225 (1):19-26.

113. Ergunay K, Saygan MB, Aydogan S, Litzba N, Niedrig M, Pinar A, et al. Investigation of dengue virus and yellow fever virus seropositivities in blood donors from central/Northern Anatolia, Turkey. Mikrobiyoloji Bulteni. 2010; 44(3):415-24. PMID: 21063991

114. Tezcan S, Kizildamar S, Ulger M, Aslan G, Tiftik N, Ozkul A, et al. Flavivirus seroepidemiology in blood donors in Mersin province, Turkey. Mikrobiyoloji bulteni. 2014; 48(4):606-17. PMID: 25492656

115. Bin Ghouth AS, Amarasinghe A, Letson GW. Dengue outbreak in Hadramout, Yemen, 2010: an epidemiological perspective. Am J Trop Med Hyg. 2012; 86(6):1072-6. doi: 10.4269/ajtmh.2012.11-0723 PMID: 22665621

116. Malik MR, Mnzava A, Mohareb E, Zayed A, AI Kohlani A, Thabet AAK, et al. Chikungunya outbreak in Al-Hudaydah, Yemen, 2011: Epidemiological characterization and key lessons learned for early detection and control. Journal of Epidemiology and Global Health. 2014; 4(3):203-11. doi: 10.1016/j.jegh. 2014.01.004 PMID: 25107656

117. Madani TA, Abuelzein ETME, Al-Bar HMS, Azhar El, Kao M, Alshoeb HO, et al. Outbreak of viral hemorrhagic fever caused by dengue virus type 3 in Al-Mukalla, Yemen. BMC Infectious Diseases. 2013; 13(1).

118. Rezza G, El-Sawaf G, Faggioni G, Vescio F, Al Ameri R, De Santis R, et al. Co-circulation of Dengue and Chikungunya Viruses, Al Hudaydah, Yemen, 2012. Emerg Infect Dis. 2014; 20(8):1351-4. doi: 10.3201/eid2008.131615 PMID: 25061762

119. Qassem MAM, Jaawal AAT. Dengue fever or West Nile virus outbreak? Yemen 2013. International Journal of Infectious Diseases. 2014; 21:457.

120. World Health Organizationj Regional Office for the Eastern Mediterranean. Dengue in Pakistan. Weekly Epidemiological Monitor. 2013; 6(52). Available www.emro.who.int/surveillance-forecastingresponse/weekly-epidemiological-monitor/. Accessed 17 Jan 2016.

121. Haider Z, Ahmad FZ, Mahmood A, Waseem T, Shafiq I, Raza T, et al. Dengue fever in Pakistan: A paradigm shift; Changing epidemiology and clinical patterns. Perspectives in Public Health. 2015; 135 (6):294-8. doi: 10.1177/1757913915599019 PMID: 26342006

122. Weaver SC, Lecuit M. Chikungunya virus and the global spread of a mosquito-borne disease. $\mathrm{N}$ Engl $\mathrm{J}$ Med. 2015; 372(13):1231-9. doi: 10.1056/NEJMra1406035 PMID: 25806915

123. Nsoesie EO, Kraemer MU, Golding N, Pigott DM, Brady OJ, Moyes CL, et al. Global Distribution and Environmental Suitability for Chikungunya Virus, 1952-2015. Euro Surveillance. 2016; 21(20):pii = 30234.

124. Koo C, Nasir A, Hapuarachchi HC, Lee KS, Hasan Z, Ng LC, et al. Evolution and heterogeneity of multiple serotypes of Dengue virus in Pakistan, 2006-2011. Virol J. 2013; 10:275. doi: 10.1186/1743422X-10-275 PMID: 24007412

125. Jimenez-Lucho VE, Fisher EJ, Saravolatz LD. Dengue with hemorrhagic manifestations: An imported case from the Middle East. American Journal of Tropical Medicine and Hygiene. 1984; 33(4):650-3. PMID: 6476211 
126. World Health Organization. Dengue: Guidelines for Diagnosis, Treatement, Prevention and Control. Geneva, Switzerland. 2009. Available at: http://www.who.int/tdr/publications/documents/denguediagnosis.pdf Accessed 1 September 2016.

127. World Health Organization Regional Office for the Eastern Mediterranean. Multiple outbreaks from DF/DHF in the EMR. 2008; 1(30). Available www.emro.who.int/surveillance-forecasting-response/ weekly-epidemiological-monitor/. Accessed 17 Jan 2016.

128. Ghouth ASB, Amarasinghe A, Letson GW. Dengue outbreak in Hadramout, Yemen, 2010: An epidemiological perspective. American Journal of Tropical Medicine and Hygiene. 1072; 86(6):1072-6. doi: 10.4269/ajtmh.2012.11-0723 PMID: 22665621

129. Burdino E, Milia MG, Sergi G, Gregori G, Allice T, Cazzato ML, et al. Diagnosis of dengue fever in North West Italy in travelers from endemic areas: a retrospective study. J Clin Virol. 2011; 51(4):25963. doi: 10.1016/j.jcv.2011.05.011 PMID: 21636317

130. Heikal OM, El-Bahnasawy MM, Morsy AT, Khalil HH. Aedes aegypti re-emerging in Egypt: a review and what should be done? Journal of the Egyptian Society of Parasitology. 2011; 41(3):801-14. PMID: 22435171

131. Ahmadnejad F, Otarod V, Fallah MH, Lowenski S, Sedighi-Moghaddam R, Zavareh A, et al. Spread of West Nile virus in Iran: A cross-sectional serosurvey in equines, 2008-2009. Epidemiology and Infection. 2011; 139(10):1587-93. doi: 10.1017/S0950268811000173 PMID: 21396143

132. Conley AK, Fuller DO, Haddad N, Hassan AN, Gad AM, Beier JC. Modeling the distribution of the West Nile and Rift Valley Fever vector Culex pipiens in arid and semi-arid regions of the Middle East and North Africa. Parasites \& vectors. 2014; 7:289.

133. Weaver SC, Reisen WK. Present and future arboviral threats. Antiviral Res. 2010; 85(2):328-45. doi: 10.1016/j.antiviral.2009.10.008 PMID: 19857523

134. Rabe IB, Staples JE, Villanueva J, Hummel KB, Johnson JA, Rose L, et al. Interim Guidance for Interpretation of Zika Virus Antibody Test Results. MMWR Morb Mortal Wkly Rep. 2016; 65(21):543-6. doi: 10.15585/mmwr.mm6521e1 PMID: 27254248

135. Kraemer MU, Sinka ME, Duda KA, Mylne AQ, Shearer FM, Barker CM, et al. The global distribution of the arbovirus vectors Aedes aegypti and Ae. albopictus. Elife. 2015; 4:e08347. doi: 10.7554/eLife. 08347 PMID: 26126267

136. Izri A, Bitam I, Charrel RN. First entomological documentation of Aedes (Stegomyia) albopictus (Skuse, 1894) in Algeria. Clinical Microbiology and Infection. 1116; 17(7):1116-8. doi: 10.1111/j.14690691.2010.03443.x PMID: 21435096

137. Haddad N, Harbach RE, Chamat S, Bouharoun-Tayoun H. Presence of Aedes albopictus in Lebanon and Syria. J Am Mosq Control Assoc. 2007; 23(2):226-8. doi: 10.2987/8756-971X(2007)23[226: POAAIL]2.0.CO;2 PMID: 17847859

138. Adawi SHAA. Presence of Aedes albopictus in Palestine-West Bank. International Journal of Tropical Disease and Health. 2012; 2(4):301-10.

139. Leshem E, Bin H, Shalom U, Perkin M, Schwartz E. Risk for emergence of dengue and chikungunya virus in Israel. Emerging Infectious Diseases. 2012; 18(2):345-7. doi: 10.3201/eid1802.111648 PMID: 22305194

140. Oter K, Gunay F, Tuzer E, Linton YM, Bellini R, Alten B. First record of Stegomyia albopicta in Turkey determined by active ovitrap surveillance and DNA barcoding. Vector Borne Zoonotic Dis. 2013; 13 (10):753-61. doi: 10.1089/vbz.2012.1093 PMID: 23808976

141. European Centre for Disease Prevention and Control. Guidelines for the surveillance of invasive mosquitoes in Europe. Stockholm: ECDC; 2012. Available at: http://ecdc.europa.eu/en/publications/ publications/ter-mosquito-surveillance-guidelines.pdf. Accessed 15 Jan 2016.

142. The World Bank Group. The Middle East and North Africa: Urban Development 2015. Available from: http://go.worldbank.org/Y88FI6V7R0. Accessed 8 Feb 2016.

143. Soghaier MA, Hagar A, Abbas MA, Elmangory MM, Eltahir KM, Sall AA. Yellow fever outbreak in Darfur, Sudan in october 2012; the initial outbreak investigation report. Journal of Infection and Public Health. 2013; 6(5):370-6. doi: 10.1016/j.jiph.2013.04.007 PMID: 23999341

144. Seidahmed O, Siam HA, Hassan SA, Mohamed SA, Abd Elrhman LS, Osman HA, et al. Vector control and surveillance during a major outbreak of dengue in a coastal Red Sea area: Port Sudan City. American Journal of Tropical Medicine and Hygiene. 2011;1: ):92.

145. Gould EA, Higgs S. Impact of climate change and other factors on emerging arbovirus diseases. Trans R Soc Trop Med Hyg. 2009; 103(2):109-21. doi: 10.1016/j.trstmh.2008.07.025 PMID: 18799177 
146. Amarasinghe A, Letson GW. Dengue in the Middle East: A neglected, emerging disease of importance. Transactions of the Royal Society of Tropical Medicine and Hygiene. 2012; 106(1):1-2. doi: 10. 1016/j.trstmh.2011.08.014 PMID: 22137535

147. Fahmy NT, Klena JD, Mohamed AS, Zayed A, Villinski JT. Complete Genome Sequence of Chikungunya Virus Isolated from an Aedes aegypti Mosquito during an Outbreak in Yemen, 2011. Genome announcements. 2015; 3(4).

148. Ciccozzi M, Lo Presti A, Cella E, Giovanetti M, Lai A, El-Sawaf G, et al. Phylogeny of Dengue and Chikungunya viruses in Al Hudayda governorate, Yemen. Infection, genetics and evolution: Journal of molecular epidemiology and evolutionary genetics in infectious diseases. 2014; 27C:395-401.

149. Rezza G, El-Sawaf G, Faggioni G, Vescio F, Al Ameri R, De Santis R, et al. Co-circulation of dengue and chikungunya viruses, Al Hudaydah, Yemen, 2012. Emerging Infectious Diseases. 2014; 20 (8):1351-4. doi: 10.3201/eid2008.131615 PMID: 25061762

150. Awaidy ST, Obeidani IA, Bawikar S, Mahrouqi SA, Busaidy SS, Baqlani SA, et al. Dengue epidemiological trend in Oman: a 13-year national surveillance and strategic proposition of imported cases. Trop Doct. 2014.

151. Cleton NB, Godeke GJ, Reimerink J, Beersma MF, Doorn HR, Franco L, et al. Spot the differencedevelopment of a syndrome based protein microarray for specific serological detection of multiple flavivirus infections in travelers. PLoS Negl Trop Dis. 2015; 9(3):e0003580. doi: 10.1371/journal.pntd. 0003580 PMID: 25767876

152. Centers for Disease Control and Prevention. Mosquito Surveillance Software. Atlanta, GA, USA 2015. Available from: http://www.cdc.gov/westnile/resourcepages/mosqsurvsoft.html. Accessed 8 Feb 2016. 